NBER WORKING PAPER SERIES

\title{
EARNINGS INEQUALITY AND COORDINATION COSTS: EVIDENCE FROM U.S. LAW FIRMS
}

\author{
Luis Garicano \\ Thomas Hubbard \\ Working Paper 14741 \\ http://www.nber.org/papers/w14741 \\ NATIONAL BUREAU OF ECONOMIC RESEARCH \\ 1050 Massachusetts Avenue \\ Cambridge, MA 02138 \\ February 2009
}

The research in this paper was conducted while the authors were Census Bureau research associates at the Chicago Research Data Center. Research results and conclusions are those of the authors and do not necessarily indicate concurrence by the Bureau of the Census. This paper has been screened to ensure that no confidential data are revealed. We thank our colleagues, particularly Kevin M. Murphy, NBER Labor Economics Summer Institute participants and participants in other workshops for their comments, and Chris Ody for excellent research assistance. The views expressed herein are those of the author(s) and do not necessarily reflect the views of the National Bureau of Economic Research.

NBER working papers are circulated for discussion and comment purposes. They have not been peerreviewed or been subject to the review by the NBER Board of Directors that accompanies official NBER publications.

(C) 2009 by Luis Garicano and Thomas Hubbard. All rights reserved. Short sections of text, not to exceed two paragraphs, may be quoted without explicit permission provided that full credit, including $\odot$ notice, is given to the source. 
Earnings Inequality and Coordination Costs: Evidence From U.S. Law Firms

Luis Garicano and Thomas Hubbard

NBER Working Paper No. 14741

February 2009

JEL No. J31,J44,L22

\begin{abstract}
$\underline{\text { ABSTRACT }}$
Earnings inequality has increased substantially since the 1970s. Using evidence from confidential Census data on U.S. law offices on lawyers' organization and earnings, we study the extent to which the mechanism suggested by Lucas (1978) and Rosen (1982), a scale of operations effect linking spans of control and earnings inequality, is responsible increases in inequality. We first show that earnings inequality among lawyers increased substantially between 1977 and 1992, and that the distribution of partner-associate ratios across offices changed in ways consistent with the hypothesis that coordination costs fell during this period. We then propose a "hierarchical production function" in which output is the product of skill and time and estimate its parameters, applying insights from the equilibrium assignment literature. We find that coordination costs fell broadly and steadily during this period, so that hiring one's first associate leveraged a partner's skill by about 30\% more in 1992 than 1977 . We find also that changes in lawyers' hierarchical organization account for about $2 / 3$ of the increase in earnings inequality among lawyers in the upper tail, but a much smaller share of the increase in inequality between lawyers in the upper tail and other lawyers. These findings indicate that new organizational efficiencies potentially explain increases in inequality, especially among individuals toward the top of the earnings distribution.
\end{abstract}

\author{
Luis Garicano \\ London School of Economics \\ luis.garicano@gmail.com \\ Thomas Hubbard \\ 615 Leverone Hall \\ Kellogg School of Management \\ Northwestern University \\ Evanston, IL 60208 \\ and NBER \\ t-hubbard@kellogg.northwestern.edu
}




\section{Introduction}

The returns to skill have risen substantially in the United States since the 1970s, as has earnings inequality. ${ }^{1}$ These increases have taken place at the same time as large changes in many firms' organizational structure which have resulted in increases in managers' "spans of control" (see e.g. Rajan and Wulf, 2006). This raises the issue of whether changes in inequality have organizational underpinnings as well. If, as Lucas (1978) and Rosen (1982) argue, highly-skilled managers are assigned greater spans of control than less-skilled managers in equilibrium, and if managers' spans are limited by coordination costs, then decreases in coordination costs can increase earnings inequality through their impact on spans of control. Recent research indicates that changes in spans are important for understanding increases in earnings inequality among at least one set of individuals; Gabaix and Landier (2008) and Tervio (2008) provide evidence that changes in firm size account for much of the post-1980 increase in earnings inequality among CEOs at very large U.S. firms. ${ }^{2}$

This paper examines these issues in the context of U.S. lawyers. How much has earnings inequality increased, how much have the coordination costs associated with hierarchical production declined, and how much of the increase in earnings inequality reflects lawyers' organizational response to changes in these costs? We propose an analytic framework based on Garicano (2000) and Garicano and Rossi-Hansberg (2006), and use this framework to answer these questions using law-office level data from the 1977, 1982, 1987, and 1992 Census of Service Industries. ${ }^{3}$

We first describe some general patterns regarding how lawyers' earnings and hierarchical organization changed during our sample period. We show that earnings inequality across lawyers increased substantially and steadily between 1977 and 1992 .

\footnotetext{
${ }^{1}$ See e.g. Katz and Murphy (1992). Card and DiNardo (2002) argue the growth does not start until 1979, while other authors date the start as early as the mid 1970s. In other countries, the growth in inequality took place but was smaller (except in the UK) and started later. See Autor and Katz (1998) for a survey and Autor, Katz, and Kearney (2007) for recent evidence.

${ }^{2}$ See also Kaplan and Rauh (2007) who find support in a wide range of settings for the idea that scale effects can account for a large portion of the change in earnings inequality at the very top.

${ }^{3}$ The evidence in this paper builds upon our previous work (Garicano and Hubbard (2007a)), which tests models of hierarchical production, proposes an econometric framework to estimate them, and estimates the returns to hierarchy at one point in time. Our sample ends in 1992 because this is the most recent year in which the Census asked law offices which fields lawyers cover; we have found that absent this information, we are unable to reliably estimate lawyers' earnings from the data the Census collects.
} 
We then document several preliminary facts that suggest that coordination costs related to working with associates also decreased over this period. First, the share of lawyers who work in offices without any associates decreased between 1977 and 1992 by one-third from about $30 \%$ to about $20 \%$. Second, the distribution of associatepartner ratios across offices changed during this period so that the most "leveraged" lawyers in 1992 were almost 50\% more leveraged than the most "leveraged" lawyers in 1977. Third, qualitatively, new information and communication technologies penetrated deeply and broadly in the industry, which contemporary accounts indicate had an important impact on how lawyers worked with each other. Together, these facts suggest that working in hierarchical teams became cheaper in the law during this period.

We then analyze these changes in more depth. We propose a production function in which there are two inputs, skill and time, and a law office's output is the product of the value of partners' skill and the time that lawyers in the office spend directly in production. ${ }^{4}$ We show that the coordination cost of hierarchical production is identified by the ratio between revenues per lawyer - the office's average product - and the marginal cost of an associate. In other words, the coordination cost of hierarchical production is the extent to which there are decreasing returns to the scale of a hierarchical team. ${ }^{5}$ Of course, returns to scale in this context are returns to heterogeneous units of inputs which are not perfect substitutes and match endogenously. Applying ideas from assignment models and the hedonics literature, we estimate this marginal cost for each office, then use this estimate in specifications that uncover the coordination costs of hierarchical production. We analyze how these costs have changed over time, and develop counterfactual exercises that allow us to assess the extent to which increases in earnings inequality reflect lawyers' organizational responses to these changes. Our estimates indicate that coordination costs declined steadily between 1977 and 1992, such that hiring one's first associate leveraged a partner's skill by about 30\% more in 1992 than 1977 . We provide some evidence that this is related

\footnotetext{
${ }^{4}$ Unlike in Lucas (1978), Rosen (1982), Gabaix and Landier (2008) and Tervio (2008), the organization of production involves endogenous matching between managers and workers; better managers not only manage more efficiency units or larger size teams, but also match with highest skilled workers.

${ }^{5}$ An alternative interpretation of this ratio is that it reflects that partners' market power. In this highly fragmented industry this is unlikely; we nevertheless consider and test this alternative explanation and find that it is unlikely to account for the changes in this ratio that we uncover.
} 
to the diffusion of Lexis, a computer-aided legal research service; however, our data do not allow us to provide definitive evidence on precisely how information technology has affected organizational structures and inequality in this industry. ${ }^{6}$ We find also that most of the increase in inequality among top lawyers between 1977 and 1992 reflects increases in associate-partner ratios that were responses to these decreases. In contrast, we find that most of the increase in inequality between top lawyers and other lawyers during this time reflects other factors that increased the market value of top lawyers' skill relative to that of other lawyers' skill, including skill-biased demand shifts. Changes in lawyers' hierarchical organization account for much of the increase in inequality within the upper tail, but little of the increase in inequality between lawyers in the upper tail and other lawyers.

Our work complements the literature on inequality by introducing coordination costs as an important factor in explaining earnings inequality. Methodologically, we do this by endogenizing organizational decisions: agents' span of control reflect optimizing behavior that trades off knowledge utilization and coordination costs. The equilibrium that we obtain depicts not only the match between individuals, but also involves differences in individuals' hierarchical organization that correspond to skill differences. We show how agents' first order conditions and equilibrium relationships between individuals' earnings and hierarchical organization can be exploited to estimate parameters that reflect coordination costs. A payoff to this is that we can not only assess the degree to which increases in earnings inequality relate to increases in spans of control, but also investigate what drives these organizational changes. Our estimates indicate not only that increases in earnings inequality among top lawyers are related to changes in lawyers' organization, but also that new organizational efficiencies (perhaps enabled by new information technologies) are at the root of these increases.

The rest of the paper is organized as follows. Section 2 documents some key facts and discusses their context. Section 3 develops our analytic framework. We propose an equilibrium model of knowledge-based hierarchies and describe how we use this

\footnotetext{
${ }^{6}$ Our data allows us to exploit the idea that decreases in coordination costs increase the returns to hierarchical production, which is related to Garicano's (2000) finding that reductions in either communication or learning costs lead to larger spans of control. But they do not allow us to exploit the idea that decreases in communication and learning costs should have different impacts on other organizational variables such as the number of hierarchical layers or the knowledge acquired at each layer.
} 
model as the basis for our empirical specifications. In Section 4, we describe our data. We report and discuss our main results in Section 5. Section 6 concludes.

\section{Earnings and Hierarchical Organization of U.S. Lawyers, 1977-1992}

\subsection{Two Stylized Facts}

We begin by describing the main patterns concerning earnings inequality and hierarchical organization in the law during this period.

1. Earnings inequality increased steadily between 1977 and 1992; this increase was particularly large at the top of the earnings distribution. Table 1 presents our estimates of various quantiles of the earnings distribution among privately-practicing U.S. lawyers between 1977 and 1992. All figures are in 1992 dollars. These estimates use confidential data from the Census of Services; the way we construct these estimates differs somewhat by year, depending on the variables the Census collects. We discuss the data and how we construct these estimates in Section 4 below.

Earnings inequality among lawyers increased steadily during this time period, and this increase was particularly large when comparing lawyers in the upper tail relative to those at other quantiles. The ratio between the 95th percentile and median earnings increased from 3.5 in 1977 to 4.8 in 1992. In contrast, the ratio between 75th percentile and median earnings was roughly constant. Figure 1 graphically depicts earnings distributions for 1977 and 1992. Earnings were lower below the 80th percentile, and greater above the 80th percentile, in 1992 than in 1977.

The steadiness in the increase in earnings inequality is striking in light of large fluctuations in earnings levels over time. These fluctuations are correlated with the business cycle, and thus the overall demand for lawyers, though they undoubtedly reflect changes in the number and composition of lawyers as well. Median real earnings dropped by $20 \%$ between 1977 and 1982, and large decreases appear in the other quantiles as well. Lawyers' earnings then increased sharply between 1982 and 1987, with the median increasing by 20\%, almost returning to the 1977 level. They then decreased slightly between 1987 and 1992. The contrast between the consistent 
increase in earnings inequality and the fluctuations of earnings levels during this period is interesting, because it suggests that increases in inequality reflect long-run phenomena that are to some extent distinct from factors that can vary from period to period. An explanation of increases in inequality that revolves only around changes in the overall demand for lawyers' services would have difficulty accommodating the fact that earnings inequality has increased not only during booms but during recessions as well: for example, not only between 1982 and 1987 but also between 1977 and 1982 .

It is unlikely that changes in earnings inequality reflect changes in the distribution of demands across areas of the law. A well-known phenomena during this time is the "litigation explosion," which raises the issue of whether changes in the demand for litigation and the supply of litigators could explain these trends. However, as we will show in greater detail later in the paper, earnings inequality increased among lawyers in both litigation-intensive (e.g., negligence and insurance law) and non-litigation intensive fields. It also is unlikely that increases in earnings inequality reflect other well-known field compositional changes. For example, demand for merger and acquisition-related legal services was likely much higher in 1987 than in 1982 or $1992 .{ }^{7}$ But as noted before, earnings inequality increased both leading up to and after this peak.

The earnings inequality patterns we find are consistent with well known findings over the same period throughout other occupations (see Katz and Murphy, 1992) and industries. Our work is the first one to be able to pair those findings with data on changes in firms' hierarchical structure and thus can provide direct evidence on the potential impact of the Lucas (1978) and Rosen (1982) type hypothesis that earnings inequality and spans of control are closely related. ${ }^{8}$ We show next that the preliminary evidence is encouraging: a second broad trend in legal services is that lawyers' hierarchical organization has changed over time. Specifically, more lawyers work in hierarchical teams and hierarchical teams have more associates per partners. We state these two facts next.

\footnotetext{
${ }^{7}$ This is reflected in changes in the field composition of lawyers as reported in our data: the share of lawyers that specialize in either banking or corporate law was $10.2 \%$ in $1982,16.8 \%$ in 1987 , then $13.2 \%$ in 1992.

${ }^{8}$ In the conclusion we address the implications for the broader literature of our finding that, indeed, these two trends are connected.
} 


\section{Lawyers' hierarchical organization changed; a greater share of}

lawyers worked in hierarchical teams, and the distribution of associates across partners became more unequal. We classify lawyers into three categories: associates, unleveraged partners, and leveraged partners, where "unleveraged" partners are partners who work in offices with no associates and "leveraged partners" are partners who work in offices with at least one associate. Our data indicates that the share of lawyers who worked as associates increased from $29 \%$ in 1977 to $40 \%$ in 1992, and the share of leveraged partners remained constant at around 40\%. Thus, the share of lawyers who worked in offices structured around hierarchical teams increased from $70 \%$ to around $80 \%$. In contrast, the share of lawyers who worked as unleveraged partners, and thus in offices not structured around hierarchical teams, decreased from about $40 \%$ to $30 \%$.

Table 2 provides evidence on the distribution of "leverage" across lawyers. "Leverage" equals zero for associates and partners at offices with no associates and equals the office's associate/partner ratio for partners at offices with at least one associate. This measure is designed to reflect how many lawyers work under a lawyer. This table shows that leverage has increased on average and has tended to become more unequal over time. The median leverage is zero throughout, while the 95 th percentile increased from 1.17 to 1.67 , or $43 \%$. The steady increase in earnings inequality across lawyers, especially comparing lawyers at the top of the earnings distribution to other lawyers, coincides with an increase in the leverage of the most leveraged lawyers.

\subsection{Potential Explanations}

The joint increase in earnings inequality and leverage is particularly striking in light of large changes in the age distribution of lawyers during this time. One possible explanation for these trends would revolve around changes in the lawyers' skill distribution: if the supply of younger, less experienced lawyers increased steadily relative to that of over older, more experienced lawyers, one would expect both increases in leverage and increases in earnings inequality simply because leverage has become cheaper over time. However, changes in the age distribution of lawyers suggest that the opposite is more likely to be the case. Table 3 indicates that the share of privately-practicing lawyers who are 35 or younger decreased by $25 \%$ (from $45 \%$ to $35 \%$ ) between 1980 and 
1990, then decreased by another 20-25\% during the 1990s. ${ }^{9}$ Earnings inequality and leverage increased between the late 1970s and early 1990s despite the fact that the number of young, inexperienced lawyers was declining relative to that of older, more experienced lawyers. It is thus difficult to explain changes in earnings inequality and leverage during this time with a theory that relies only on changes in the experience distribution of lawyers.

Two classes of explanations that can more easily reconcile these patterns are changes in the organizational cost of leverage and skill-biased changes in clients' demands. If the organizational costs of working with associates declined steadily over time, and the marginal benefits of hiring associates is greater for more skilled lawyers, one would expect leverage and earnings to increase disproportionately at the top of their respective distributions over time. This would be true even if the distribution of clients' demand for skill stayed constant. Alternatively, if clients' demand for the most skilled lawyers increased steadily during this time relative to that for less-skilled lawyers, one would expect steady increases in earnings inequality. One would also expect leverage to increase, even if the organizational costs of working with associates did not change.

An empirical goal of this paper is to shed light on these explanations. We will estimate changes in the organizational cost of leverage ("coordination costs"), and distinguish between changes in lawyers' earnings distribution that are directly associated with changes in leverage versus changes in the market value of individual lawyers' time. This exercise directly illuminates the first of these explanations; for example, we are able to assess how much less earnings inequality would be if leverage in 1992 was instead at 1977 levels. It indirectly illuminates the second of these explanations, since changes in the market value of lawyers' time reflect not only any skill-biased changes in demand, but also changes in the distribution of lawyers' skills as well. One possibility with respect to the latter is that decreases in coordination costs could lead to a spreading out of the skill distribution by disproportionately increasing the returns to human capital investment for the most skilled lawyers.

The next subsection places these changes in their institutional context, highlight-

\footnotetext{
${ }^{9}$ These figures reflect a large, well-known demographic bulge among lawyers that is also manifested by time trends in the entry of new lawyers into the profession. New admissions to the bar increased by $50 \%$ from 20,510 to 30,707 between 1971 and 1973 , reached 42,756 in 1979, then stabilized (Abel (1989), Table 21). Changes in the age distribution of lawyers since 1970 have reflected the entry and aging of these cohorts, which were far larger than those that preceded them.
} 
ing several important technological changes that affected how lawyers worked with one another during our sample period.

\subsection{Technological Change In Law Offices, 1977-1992}

Three new technologies had an important affect on how lawyers generated output during this time: computer-aided legal research systems, word processors, and internal email systems.

The commercialization and diffusion of computer-aided legal research systems such as Lexis and Westlaw lowered lawyers' cost of retrieving information. These services were first offered in the mid-1970s. By the late 1970s many of the largest firms subscribed to at least one of these services, which were usually accessed through one or more dedicated terminals in the firm's office. The cost of these services at the time was very high (over $\$ 100 /$ hour plus the price of leasing terminals) and the coverage of the databases was limited, so very few small and medium-sized firms chose to subscribe themselves, although many lawyers at such firms had access through publically accessible law libraries. Decreases in the price of both the hardware and these services and increases in their coverage led these services to become common in all but the very smallest offices by the early 1990s, and they are currently available as web-based applications. ${ }^{10}$ These services fundamentally changed how lawyers conducted research. Before these services, lawyers depended on paper trails and the memories of their colleagues to find the pertinent information they needed for their work.

Document production changed during this time as well. At the start of the period, practically all documents were typed by hand, often in duplicate, and the physical copies were stored in lawyers' case files. This process changed, first with the development of faster, cheaper photocopiers, then with the diffusion of word processing machines starting in the early 1980s. These machines, which were highly specialized computers, allowed lawyers (or, more precisely, their secretaries) to revise documents without having to retype them entirely and to retain electronic copies of any documents that they produced. The ability to revise documents without having

\footnotetext{
${ }^{10}$ Although Federal law databases were available on these services in the mid-1970s, state law databases were added to these services gradually. Below we will describe how we exploit cross-state differences in the availability of Lexis state law databases to examine whether the coordination cost decreases we uncover are related to the diffusion of these services.
} 
to retype them entirely was valuable not just because it saved the time of retyping documents, but also because it reduced the time spent checking documents since one could focus attention on parts that had changed. The ability to maintain electronic copies was extremely valuable to lawyers because it allowed them to easily reuse text. Most lawyers had files of forms that they used to construct standard documents, but until documents were stored electronically, reusing text from previously-developed documents required them to retrieve the hard copies and retype the relevant text into the new document. PC-based word processing applications gradually replaced specialized word processing machines throughout the 1980s. These offered similar functionality, but were far cheaper, and extended these capabilities to smaller law offices. The change in computing platform from specialized machines to PCs did not immediately change how documents were produced in most cases; PCs at first simply replaced specialized word processing machines on secretaries' desks. ${ }^{11}$ By the early 1990s, word processing applications had been adopted at most law firms, even small ones, though they were not necessarily used directly by the lawyers themselves.

Finally, the way lawyers communicated with each other and with clients changed as well. The most important change in intra-office communication was the diffusion of electronic mail, which occurred late in our sample period and primarily in the largest offices. Personal computers became common on lawyers' desks, first at large firms, in the late 1980s and early 1990s. Adoption of PCs by lawyers themselves generally coincided with the adoption of local area networks which linked these machines together with each other and printers, and which supported intra-office electronic mail. ${ }^{12}$ Email not only provided a new way that lawyers could communicate with each other, but also allowed them to more easily share and edit electronic versions of documents. External communication changed throughout our sample period; fax machines became common in law offices during the 1980s, and teleconferencing and videoconferencing became more affordable throughout this period. Lawyers' use of email for external communication was uncommon until the mid-1990s commercialization of the internet, however.

\footnotetext{
${ }^{11}$ A 1985 Survey by Hildebrandt, Inc. reports that most large firms had one or more PCs, but the majority of these were used by secretaries and administrators.

${ }^{12}$ Staudt and Shiels (1994) provide evidence that by 1993, most lawyers in large firms had personal computers on or near their desks, and the vast majority of large law firms had installed local area networks. The diffusion of networked PCs was very rapid; in the mid-1980s, these were extremely rare.
} 
Thus, technological change fundamentally altered how lawyers accomplished three important tasks during this period. Each of these changes had their greatest initial impact on large firms first before diffusing to smaller ones, but they took place at different points in time. Information retrieval improved starting in the late 1970s, particularly for lawyers in states where on-line databases included state law as well as Federal law. Document production changed starting in the early 1980s, and intra-office communication costs decreased starting in the late 1980s.

All of these changes decrease coordination costs. The impact of email and other means of electronic communication on coordination costs is straightforward. More subtly, the diffusion of computer-aided legal research decreased coordination costs by reducing the degree to which associates relied on partners' guidance to find relevant material; the results of search queries provide associates guidance that sometimes substitutes for partners' expertise. Finally, the adoption of word processing applications diminished coordination costs by making it less costly for teams of lawyers to edit and unify text that was drafted by different individuals into a single document. A broad consequence of these changes is that partners can delegate work to associates more efficiently than they could in the past, allowing for an increase in the leverage of partner talent.

\section{The Impact of Coordination Costs On Organi- zation and Inequality: Theoretical Framework}

\subsection{Theoretical model}

In this section, we study the equilibrium relationship between coordination costs, organization, and earnings. To do this, we proceed in two steps. We first analyze theoretically the impact of coordination costs on organization and earnings inequality with the help of a simple equilibrium model. We then use the model to construct our empirical specifications.

We consider an environment where agents are endowed with one unit of time and unidimensional skill $z \sim g(z), z \in[\underline{z}, \bar{z}], \underline{z}>0$. We measure this skill in dollar value of output that an agent can produce when working on their own. We propose that hierarchical teams allow agents to combine their knowledge with other agents' time as well as their own. Specifically, we assume that the output of a hierarchical team 
with one manager of skill $z_{m}$ and $n$ workers of skill $z_{w}$ is $y=z_{m} f\left(n\left(z_{w}\right)\right)$, where $n$ is the number of workers, $f(n)$ is the effective time in production the $n+1$ individuals spend, and $f(0)=1$. We assume that managers' span of control is limited by their workers' skill; increasing a manager's span of control $n$ requires them to delegate a larger share of their team's work, and this in turn requires them to have more-skilled workers. To capture this relationship, we assume that $n^{\prime}\left(z_{w}\right)>0 .{ }^{13}$

For estimation purposes, we further specify $f(n)=(n+1)^{\theta}$, with $0 \leq \theta \leq 1$. If $\theta<1$, then the effective time in production of the team is less than the agents' time endowment $n+1 ; \theta$ parameterizes the coordination cost associated with hierarchical production. Note that such costs do not exist if agents work on their own; if $n=0$, $f(n())=.1 .^{14}$ Our hierarchical production function is thus:

$$
y=z_{m}\left(n\left(z_{w}\right)+1\right)^{\theta} .
$$

In contrast, the output of these $n+1$ agents is $z_{m}+n z_{w}$ if they worked on their own. The benefit of hierarchical production is that the manager's knowledge is applied to others' time as well as their own, and the team's productivity per unit of time in production is higher than when they work on their own. The drawback is that agents spend a lower share of their time directly in production.

In Garicano and Hubbard (2007a), we set up and solve for the equilibrium of this model, show that it exists, develop testable implications of this model and find evidence in favor of these implications. Unlike in our previous work, this paper uses the model as a maintained assumption throughout our empirical work. In what follows, we only sketch the equilibrium construction; the only new results concern the comparative statics, which bear on how changes in coordination costs affect earnings inequality in equilibrium. The reader is directed to the companion paper for the rest of the equilibrium proofs.

The organizational equilibrium in this model determines: (a) the allocation of agents of skill $z$ to positions - agents can become workers, managers, or "unleveraged" individuals who do not work in a team, (b) the match between workers and managers, including the number of workers with whom each manager works, and (c) agents'

\footnotetext{
${ }^{13}$ See Garicano (2000) for a derivation of this condition from first principles in a problem solving hierarchy.

${ }^{14}$ Although we label $\theta$ as "coordination costs," it includes any inefficiency that arises when individuals work in teams but not when they work on their own, including for example agency costs.
} 
earnings. An equilibrium is defined as an outcome in which no agent would be better off by switching teams or positions. As discussed in our earlier work (see Garicano and Hubbard, 2007a), the organizational equilibrium obtained in this model has the following properties:

- Positive Sorting. More knowledgeable managers work with more knowledgeable workers.

- Scale Effects. More knowledgeable managers work with larger teams of workers.

- Stratification. There exist thresholds $\left(z_{1}, z_{2}\right)$ that partition agents into positions according to their knowledge: agents with $z<z_{1}$ are workers, agents with knowledge $z>z_{2}$ are managers, and those in between are "unleveraged."

Given these properties of the competitive equilibrium, to solve for the equilibrium one must obtain a duple $\left\{z_{1}, z_{2}\right\} \in R^{+}$such that all of the agents in $\left[\underline{z}, z_{1}\right]$ are workers; those in $\left[z_{1}, z_{2}\right]$ are "unleveraged," and those in $\left[z_{2}, \bar{z}\right]$ are managers; a matching function $m:\left[\underline{z}, z_{1}\right] \rightarrow\left[z_{2}, \bar{z}\right]$ that maps the skill of workers to the skill of the manager they are assigned to; and a wage function $w(z)$ for $z \in\left[\underline{z}, z_{1}\right]$ and an earnings function $R(z)$ for $z \in\left[z_{2}, \bar{z}\right]$ that determine the earnings of workers and managers, respectively; such that: (i) each manager's optimal choice of worker quality $z_{w}$ is the one prescribed by the matching function, $z_{m}=m\left(z_{w}\right)$; (ii) the matching function is such that the supply and demand of workers is equalized at all points in the distribution of skill; (iii) occupational choices are optimal.

Figure 2 depicts agents' equilibrium earnings as a function of their skill in equilibrium. The equilibrium earnings function is the outer envelope of curves that characterize how much an agent with knowledge $z$ would earn on their own, as a worker, and as a manager. From the discussion above, the earnings of agents with knowledge $z$ and who work on their own $(n=0)$ equal $R(z, 0)=z$. This is what individuals would earn, absent hierarchical production. The other two curves, $R(z, n)$ and $w(z)$, are the outcome of a competitive labor market equilibrium. We next sketch the construction of this competitive equilibrium, with an emphasis on the objects that we use in our estimation. We will use this characterization to obtain some comparative statics results concerning the impact of changes in coordination costs on equilibrium earnings and organization. 
Consider first condition (i) in the definition above. For a given manager-worker match $z_{m}=m\left(z_{w}\right)$ to be optimal, the worker's earnings must be such that it is optimal for a manager with skill $z_{m}$ to be matched with workers of skill $z_{w}$. Managerial earnings are given by:

$$
R\left(z_{m}, n\right)=\max _{z_{w}} z_{m}\left(n\left(z_{w}\right)+1\right)^{\theta}-n\left(z_{w}\right) w\left(z_{w}\right)
$$

where $w(z)$ is the equilibrium wage function that relates workers' earnings to their skill, which we obtain below. A necessary condition in equilibrium is that each manager chooses $z_{w}$ optimally given $w(z)$; thus the first order condition:

$$
\theta z_{m}\left(n\left(z_{w}\right)+1\right)^{\theta-1}=w\left(z_{w}\right)+\frac{w^{\prime}\left(z_{w}\right)}{n^{\prime}\left(z_{w}\right)} n\left(z_{w}\right)
$$

holds for each manager. The unknowns in this first order condition are $w^{\prime}($.$) and$ $w($.$) . That is, the first order condition determines the differential equation in w$ that must hold for managerial choices of worker skill to be optimal. This equation, together with the terminal condition that the marginal worker is indifferent between being a worker or working on their own, $w\left(z_{1}\right)=z_{1}$, determines the wage function as a function of the (to be determined) cutoff $z_{1}, w\left(z ; z_{1}\right)$.

Note that for the purposes of our empirical estimation later, one can exploit the invertibility of $n\left(z_{w}\right)$ and rewrite the first order condition (3) in terms of $n$ as:

$$
\theta z_{m}(n+1)^{\theta-1}=w(n)+w^{\prime}(n) n
$$

which will allow us to characterize managers' problem in terms of their demand for leverage rather than their demand for skill.

Consider now equilibrium condition (ii) above, that supply and demand be equal at all points in the distribution. Formally, writing managerial skill in terms of the matching function $z_{m}=m\left(z_{w}\right)$ to replace $z_{w}$ in $n\left(z_{w}\right)$ by $n\left(m^{-1}\left(z_{m}\right)\right)$ :

$$
\int_{\underline{z}}^{z} g(t) d t=\int_{z_{2}}^{m(z)} n\left(m^{-1}(z)\right) g(z) d z, \forall z \leq z_{1},
$$

The left hand side is the supply of workers between $\underline{z}$ and $z$. The right hand side is the demand of workers by the managers matched with these workers, that is by the managers between $z_{2}=m(\underline{z})$ and $m(z)$. This integral equation implies a shape for the matching function, which, together with terminal condition $m\left(z_{1}\right)=\bar{z}$ (the best 
workers are matched with the best managers), results in the equilibrium matching function $m\left(z ; z_{1}\right)$.

We have now functions $m\left(z ; z_{1}\right)$ and $w\left(z ; z_{1}\right)$ that depend on the cutoff $z_{1}$. To solve for this cutoff we have two conditions left. First, market clearing requires that the least-skilled worker be matched with the least-skilled manager, $m\left(\underline{z} ; z_{1}\right)=z_{2}$. Second, continuity of the overall earnings function requires that the least-skilled manager is indifferent between working on their own or being a manager, $z_{2}=R\left(z_{2}\right)$. These functions and conditions imply a system of two equations with two unknowns that fully characterizes the equilibrium. In the proof of Lemma 1 in the Appendix we show that if a solution exists it is unique and further characterize the equilibrium.

Stratification implies that the slopes of the segments of the overall earnings function are ordered in the way depicted in Figure 2 (the slope of the self employment income is 1 , the slope of the manager's earnings function is $(n+1)^{\theta}>1$ and the slope of the wage function is $\left.w^{\prime}(z)<1\right)$. Thus occupational choices are optimal as long as the overall earnings function is continuous, which we have ensured through the conditions $z_{2}=R\left(z_{2}\right)$ and $z_{1}=R\left(z_{1}\right)$.

We are interested in studying the impact of a change in $\theta$ on equilibrium organization and inequality. Intuitively, an increase in $\theta$ increases the marginal benefit of leverage, and thus must lead to an increase in managerial earnings and leverage as managers seek to hire more workers. A first step to obtain this result as an equilibrium outcome is to characterize the impact of a change in $\theta$ on the share of managers and workers in the economy.

Lemma 1 A decrease in coordination costs (an increase in $\theta$ ) increases the share of workers ( $z_{1}$ increases) and the share of managers ( $z_{2}$ decreases) at the expense of a reduction in the share of "unleveraged" agents.

Given the characterization of $z_{1}$ and $z_{2}$, the characterization of changes in inequality and organization in equilibrium is straightforward.

Proposition 2 (Coordination Costs) A decrease in coordination costs (an increase in $\theta$ ) has the following effects on organization and inequality:

1. Organization: An increase in the proportion of workers (increase in $z_{1}$ ) and managers (decrease in $z_{2}$ ) in the economy at the expense of a decrease in the 
proportion of self-employed. The increase in the number of workers is larger than the increase in the number of managers. It also results in an increase in the span of control ( $n$ ) of each manager, as well as of the average manager, where the last result takes into account the expansion in the share of managers in the economy (that is, the least skilled manager is less-skilled than before).

2. Inequality: An increase in the return to skill for managers, $R^{\prime}(z)$, and in the pay gap among managers $\left[R(\bar{z})-R\left(z_{2}\right)\right]$.

Our empirical work, which estimates how much the coordination cost parameter $\theta$ has changed over time for lawyers and assesses how much of the increase in earnings inequality among lawyers reflects changes in lawyers' hierarchical organization, provides quantitative evidence that bears on this proposition. In passing, we note that the model above does not generate propositions regarding all possible measures of earnings inequality. To see this, note that decreases in $\theta$ will lead to increases in $z_{1}$ and thus $w(z)$; decreases in coordination costs will lead to earnings increases at the bottom as well as the top of the earnings distribution, and earnings ratios that compare the highest and lowest quantiles may or may not increase. Our proposition is nevertheless useful for two reasons. One is that it illuminates the mechanism through which coordination costs can lead inequality to increase: inequality can increase both because of a direct impact on the returns to skill and through general equilibrium effects that operate through the matching between workers and managers. The other is that our primary empirical focus will be on lawyers at or above median earnings, and the vast majority of these individuals are either unleveraged or are leveraged partners, not associates. Our analysis will thus concentrate on parts of the earnings distribution where the mechanism we describe in the proposition would be generally expected to lead earnings inequality to increase in response to decreases in coordination costs.

\subsection{The Empirical Model}

This subsection develops our empirical framework, which is the same as that in Garicano and Hubbard (2007a). This framework centers around maximization problem (2) and first order condition (4) and exploits the existence of an equilibrium wage function $w(n)$, and consequently the invertibility of $n\left(z_{w}\right)$. Doing this requires adapting 
the theoretical model to our empirical context by introducing stochastic elements into the model and accounting for inputs other than lawyers' human capital.

\subsubsection{Partners' Maximization Problem and the Demand for Leverage}

We specify a partner's earnings in office $i$ as:

$$
\begin{aligned}
R_{i}\left(z_{m i}, n\right) & =\widehat{z}_{m i}\left(n_{i}+1\right)^{\theta}-w_{i}\left(n_{i}\right) n_{i}-c_{i}\left(n_{i}\right) \\
& =\varepsilon_{i} z_{m i}\left(n_{i}+1\right)^{\theta}-w_{i}\left(n_{i}\right) n_{i}-c_{i}\left(n_{i}\right)
\end{aligned}
$$

This specification, which exploits the invertibility of $n\left(z_{w}\right)$, has two differences from equation (2). One is that we introduce a stochastic shock, $\varepsilon_{i}$, to the partner's revenues. We assume that this is a short-run demand shock realized after the partner chooses how many associates to hire; this reflects that the fact that clients' demands for legal services are uncertain, and this leads to variation in revenues conditional on the skills and size of the legal team. The timing of this shock implies that its realization affects partners' earnings but not the organizational equilibrium we depict above. We assume that $\varepsilon_{i}$ is i.i.d., positive, and $E\left(\varepsilon_{i}\right)=1$. The other difference is the term $c_{i}\left(n_{i}\right)$, which reflects law offices' costs other than associate pay. We defer a discussion of the details of our specification of these costs, which include things such as nonlawyer pay and overhead, until after we describe our data.

Partners choose $n$ to maximize expected earnings, which produces the first order condition:

$$
\theta z_{m i}\left(n_{i}+1\right)^{\theta-1}=w\left(n_{i}\right)+w^{\prime}\left(n_{i}\right) n_{i}+c_{i}^{\prime}\left(n_{i}\right)
$$

Solving for $z_{m i}$, substituting the expression into (6), then rearranging terms and taking logs, we obtain:

$$
\begin{aligned}
\ln \frac{\left[R_{i}+w_{i} n_{i}+c_{i}\left(n_{i}\right)\right]}{\left(n_{i}+1\right)}-\ln \left(w_{i}^{\prime}\left(n_{i}\right) n_{i}+w_{i}+c_{i}^{\prime}\left(n_{i}\right)\right) & =-\ln \theta+\ln \varepsilon_{i} \\
\ln A R_{i}-\ln M C_{i} & =-\ln \theta+\ln \varepsilon_{i}
\end{aligned}
$$

where $A R_{i}$ and $M C_{i}$ are the average revenues per lawyer and the marginal cost of leverage at office $i$. The coordination cost parameter $\theta$ is thus identified by the ratio between marginal cost and average revenue. If these quantities are equal on average, this implies that hierarchical production is constant returns to scale in the sense that there are no additional coordination costs associated with working with 
larger teams with greater associate-partner ratios. If marginal cost is much lower than average revenues, in contrast, this implies that there are sharply diminishing returns to leverage: hierarchical production involves considerable coordination costs that reduce the time lawyers spend in production. How the parameter $\theta$ evolves over time will be of particular empirical interest because it will affect our estimate of how much increases in earnings inequality across lawyers reflect organizational improvements versus other factors.

Average revenues per lawyer at office $i$ is observed directly in our data, but the marginal cost of leverage is not. We next turn to our specification of one of the components of this cost, $w_{i}^{\prime}\left(n_{i}\right)$.

\subsubsection{The Marginal Price of Leverage}

Our empirical specification of the function that relates associate earnings to leverage aims to relax the deterministic relationship between these variables while preserving the unidimensional sorting that characterizes the organizational equilibrium we depict above. We specify $w_{i}\left(n_{i}\right)$ as $w_{i}(n)=w(n) \xi_{i}$, where $\xi_{i}$ is a mean one log-normally distributed random variable. We interpret $\xi_{i}$ as a compensating differential that accounts for differences in working conditions at office $i$ : this factor shifts up or down all potential associates' willingness to work at office $i$. The wage-leverage surface that partners at office $i$ face equals a market wage-leverage surface $w(n)$ times an additional term that leads associate pay to be particularly high or low, conditional on the organization and skill of the lawyers at office $i{ }^{15}$ Suppressing controls, we let $\ln w(n)=\beta_{0}+\beta_{1} n+\beta_{2} n^{2}$, so that

$$
\ln w_{i}(n)=\beta_{0}+\beta_{1} n+\beta_{2} n^{2}+\eta_{i}
$$

The marginal wage $w^{\prime}(n)$ that partners at office $i$ confront is therefore $\left(\beta_{1} n+\beta_{2} n^{2}\right) w_{i}(n)$. We regress the log of associate earnings on a polynomial of $n$ and use the coefficient estimates to construct an estimate of the marginal wage, $\widehat{w_{i}^{\prime}(n)}$, for each office, which we then substitute for $w_{i}^{\prime}\left(n_{i}\right)$ in equation (8).

We allow for the possibility that associate earnings are systematically higher in some markets than others and in some fields than others by including county fixed

\footnotetext{
${ }^{15}$ If $\xi_{i}$ is independent of $n$, it must be independent of $z_{m}$ as well because $z_{m}$ and $n$ move together in equilibrium.
} 
effects and the field shares of lawyers in office $i$ as controls. We permit $w_{i}(n)$ to be determined by more-narrowly-defined labor markets by allowing the shape of $w(n)$ to differ for offices that serve litigation versus non-litigation-related demands and within the latter, that serve business versus individual demands. We have also explored the possibility that it varies across differently-sized geographic markets, but have not found evidence that this is the case. The specifications we report below therefore allow $w^{\prime}(n)$ to vary across broadly-defined classes of demand, but not across geographic markets. ${ }^{16}$

\subsubsection{Discussion}

Production Function Estimation and Hedonics Our empirical goal is to estimate the parameter $\theta$ of the hierarchical production function. Our methodology, however, differs from usual production function estimation in how it treats human capital. The usual approach is to measure labor or human capital in efficiency units, which implicitly assumes that the quality and quantity of human capital are perfect substitutes. In contrast, our framework explicitly accounts for the possibility that the quality and quantity of human capital are not perfect substitutes: knowledgeable agents can solve problems that no number of less-knowledgeable agents can. We view this as an important characteristic of the market we are studying. This aspect of human capital affects equilibrium labor market outcomes by leading partners to bid up the wages of more knowledgeable associates, and allows the marginal price of skill to be increasing in skill rather than constant. Accounting for this aspect of human capital intensive production allows us to better model and estimate the marginal cost of leverage.

Our analytic framework accounts for this by exploiting close connections between equilibrium assignment models and the hedonics literature (Rosen (1974)), both of which revolve around the equilibrium matching between heterogeneous buyers and sellers. The hierarchical production function that we propose, which has microfoundations in organizational economics, implies an invertibility property that eliminates the empirical problem of sorting on unobserved (to the econometrician) skill, a problem that arises even in unidimensional skill models. The problem is stated in terms of the supply and demand for leverage, which we observe directly, rather than for skill,

\footnotetext{
${ }^{16}$ We have also included higher-order polynomial terms, but have found that this adds little explanatory value.
} 
which we do not. In addition, our production function and data allow us to circumvent the usual identification problems that plague hedonic estimation by appealing to an identification principle that is standard in the production function literature. $\theta$ can be thought of as a parameter that affects the demand for leverage. Epple (1987) discusses the problems in finding cost shifters that, in a hedonic equilibrium, are independent of unobservables on the demand side. We can identify this parameter from the ratio between the average benefit and marginal cost of leverage and our production function implies that the average benefit of leverage is simply revenues per lawyer, which we observe in our data. ${ }^{17}$

Biases and Their Likely Magnitude Our analytic framework assumes that agents make decisions to maximize their current earnings, conditional on their knowledge. This assumption produces a labor market equilibrium in which all partners face the same wage-leverage surface (apart from the shift incorporated in $\xi_{i}$ ), and therefore the hedonic earnings regression uncovers a marginal price schedule that every partner faces. This assumption is not innocuous in this context; in particular, it rules out the possibility that agents' decisions reflect forward-looking objectives: for example, associates might value working with more knowledgeable partners because doing so would increase their future earnings through better training or client contacts. If so, the marginal price schedule implied by our regression will understate the marginal price of leverage that partners actually face. A partner who wants to hire slightly more knowledgeable associates has to compete with a slightly-more skilled partner to do so, and this would require this partner to offer more when associates value working with more knowledgeable partners than he or she would if they did not, because this partner would have to compensate associates to forego any dynamic benefits of working with a more-skilled partner. Under this alternative assumption, our estimates of the marginal cost of leverage will be biased downward, and this will lead our estimate of $\theta$ to be biased downward. ${ }^{18}$ Our counterfactuals will then understate the effect of

\footnotetext{
${ }^{17}$ See Garicano and Hubbard (2007a) for an extended discussion of the relationship between this framework, the hedonics literature, and production function estimation.

${ }^{18}$ A similar downward bias would exist if part of the true marginal cost of an associate is the expected value of any transfer from incumbent partners to associates once they are promoted. The existence of such prizes would lead us to understate the marginal cost of leverage. As explained in Garicano and Hubbard (2007a), we are skeptical of this view because it ignores the prospective clientgeneration-related benefits of promoting promising lawyers; from incumbent partners' perspective, it is probably not a cost to promote lawyers who are expected to be at least as productive as existing
} 
hierarchy on the earnings distribution, because we would mistakenly infer that coordination costs eat up too much of its potential benefits. As we discuss below and in our earlier work, the practical effect of this bias turns out to be relatively small, because the marginal price of leverage is generally a small part of the marginal cost of leverage.

Another, more mechanical, bias arises because we estimate equation (8) using OLS; applying Jensen's inequality, $E\left(\varepsilon_{i}\right)=1$ implies $E\left(\ln \varepsilon_{i}\right)<0$, which implies that our estimate of $\theta$ is biased upward. This bias is very small and is similar across years, on the order of 0.02 relative to a mean value of $0.55-0.70 .^{19}$

Our discussion of the results will not emphasize these biases, because accounting for them would have only a small effect on our estimates and even less on our inferences, which are largely based on changes over time.

Competition and $\theta$ Our analytic framework assumes that legal services markets are competitive, and thus the price that partners receive for their office's output does not decline if they choose to leverage their skill by hiring more associates. This assumption corresponds to the fact that legal services in general is a very unconcentrated industry; even the largest law firms are quite small relative to the size of the industry as a whole. ${ }^{20}$ Under this assumption, the ratio of average revenues and marginal costs reveals diminishing returns to scale associated with coordination, not downward-sloping demand curves. If, however, partners were not price takers, this ratio would reflect diminishing returns associated with downward-sloping demand curves as well and our estimates of $\theta$ would overstate the contribution of coordination costs to diminishing returns. This, in turn, would lead us to understate hierarchical

partners.

${ }^{19}$ We estimated the equation under the assumption that $\varepsilon_{i}$ is distributed log-normally, exploiting the fact that under $\log$-nomality $E\left(\varepsilon_{i}\right)=1$ implies $\ln \varepsilon_{i}$ is distributed $N\left(-\sigma^{2} / 2, \sigma^{2}\right)$. The magnitude of the bias is then $-\sigma^{2} / 2$.

${ }^{20}$ To put this into perspective, Bureau of the Census (1996) reports that in 1992 the 50 largest law firms collectively accounted for only $9 \%$ of the industry's revenues. Assuming that the industry is segmented between firms that serve individuals and firms that serve businesses, and that all of the largest law firms serve only businesses, the national C50 increases only to 18\% (since about half of industry receipts are from businesses). Even this higher measure puts it among the least concentrated business services industries; it is similar to the concentration levels of other services businesses use such as commercial photography, employment agencies, and architectural services. It is much higher than the C50s of some individual-oriented service industries use such as physicians and dentists. 
production's contribution to earnings inequality because we would be overstating the extent to which coordination costs dissipate the benefits from hierarchical production. Cross-sectional comparisons between the actual earnings distribution and what it would be absent hierarchical production will therefore provide a lower bound of the effect of hierarchical production on earnings distributions in each year.

That said, it is reasonable to consider the possibility that lawyers in some more narrowly-defined geographic or product markets face downward-sloping demand curves, and that this might have changed over time in ways that might explain our estimates of how $\theta$ evolved during our sample period. For example, law offices in very small markets might have faced downward-sloping demand curves early in our period because of a lack of local competition, but this may have become less true over time as bigger-city law firms began to serve small cities, sometimes through local branches. Alternatively, large firms based in large cities may have faced increasing competition over time as firms based in other large cities entered their home markets. Either of these would lead our estimates of $\theta$ to increase over time, even if coordination costs did not change. Therefore, finding that changes in $\theta$ over time reflect only small market offices or large offices in large cities would give us pause, because such changes could plausibly reflect sources of diminishing returns other than coordination costs. In contrast, finding that changes in $\theta$ within these subsamples are no larger (or are smaller) than changes in $\theta$ within subsamples that have faced high levels of competition throughout our sample period - such as small firms in large cities - would indicate that the changes in $\theta$ that we uncover likely reflect changes in coordination costs rather than systematic changes in the shape of the demand curves partners face.

\section{Data}

Our analysis uses confidential law-office-level data from the 1977, 1982, 1987, and 1992 Census of Services. These data include each office's revenues, employment, and payroll as reported to the Internal Revenue Service for tax purposes. They also include more detailed information collected by questions specifically asked to law offices. We observe the total number of lawyers, the number of associate lawyers, and the number of nonlawyers that work out of the office. We also observe "payroll by occupation" - total payroll to associate lawyers and to nonlawyers - and thus observe average associate pay and average nonlawyer pay at each office. We observe the 
share of lawyers that work primarily in each of 13 fields defined by the Census (e.g., corporate law, tax law, domestic law) and the share of lawyers who work in multiple fields ("general practitioners"). Finally, we observe the share of the office's revenues that come from clients who are individuals versus businesses or governments. These law-office-level data are collected from a large sample of law offices which includes nearly all law offices with at least 20 employees or that are part of multi-office firms, plus a sample of other offices. All estimates reported in this paper are computed using the Census' sampling weights. The set of law offices that receives a survey form for these data varies from year to year; therefore, our data are repeated cross-sections rather than a panel.

Our main analysis in each year uses only data from offices legally organized as partnerships or proprietorships, and not those legally organized as "Professional Service Organizations" (PSOs) such as Professional Corporations. The reason for this is that the Census asks respondents to classify lawyers according to how they are treated for tax purposes; all lawyers at firms organized as PSOs therefore are considered "associate lawyers," even though lawyers at such firms distinguish among themselves in the same way that lawyers at firms legally organized as partnerships do. The analytic framework we describe above requires data that distinguishes between partners and associates, and therefore cannot directly utilize the observations of offices organized as PSOs. ${ }^{21}$

\subsection{Estimating Partners' Earnings}

The Census does not ask law firms to report partners' earnings. We therefore must estimate this variable. This is straightforward in 1977 and 1982 because the Census asks respondents to report their total expenses in these years, along with the variables described above. We estimate partners' earnings in each office in these years as just the difference between revenues and operating expenses, divided by the

\footnotetext{
${ }^{21}$ We do not believe that this leads to any significant selection issues. PSOs were introduced by states to allow the fringe benefits lawyers and other professionals pay themselves to have same tax advantages as those they pay employees. While firms' legal form of organization varies systematically across states (corresponding to differences in when different states began to allow PSOs), conditional on state, there is not a strong relationship between firms' LFO and observables such as office size and lawyers' fields. This is reflected in the fact that in 1992, firms organized as PSOs made up about $1 / 3$ of the industry measured in terms of either lawyers, offices, and revenues. (Garicano and Hubbard (2007b))
} 
number of partners. ${ }^{22}$ Estimating partners' earnings is less straightforward in 1987 and 1992 because the Census did not ask respondents to report operating expenses. Although we observe payroll, we do not observe fringe benefits or non-payroll-related operating expenses ("overhead"), the most important components of which for law offices include rental and lease payments, communication, office supplies, and "passthrough" expenses that are billed at cost to clients such as travel expenses or charges for non-lawyer experts such as engineers (e.g., for patent cases) or economists (e.g., for antitrust cases). For partnerships and proprietorships, the difference between revenues and payroll - which we can compute directly - equals the sum of partner earnings, fringe benefit expenses, and overhead.

We estimate partners' earnings for 1987 and 1992 using the same method as in Garicano and Hubbard (2007a). We exploit the fact that (a) for firms organized as PSOs, the difference between revenues and payroll equals the sum of fringe benefit expenses and overhead, since payroll includes the earnings of all lawyers (and nonlawyers), and (b) fringe benefits are consistently about $15 \%$ of payroll at law offices Our estimate of overhead at offices organized as PSOs is therefore (revenues $1.15^{*}$ payroll). Using these offices, we regress our overhead estimate on characteristics of the office, including revenues, the number of people in the office, lawyers' fields, and local market size, allowing the relationships between overhead and revenues to be nonlinear and different across lawyers' fields, and allowing the relationship between overhead and the number of people in the office to differ with local market size (perhaps because office space is more expensive in larger markets). We then use the coefficient estimates from this regression to generate predicted values for overhead for each of our partnerships and proprietorships. Finally, we generate estimates of partner pay for each of our partnerships and proprietorships by subtracting the sum of estimated overhead and $1.15^{*}$ payroll from the office's revenues, and dividing by the number of partners. This procedure produces estimates of partner pay analogous to those generated from the 1977 and 1982 data.

This procedure generates the earnings distributions we reported in Table 1 and discussed earlier. We have compared these distributions to those generated from other sources, in particular lawyer-level earnings data from the Census' Public Use

\footnotetext{
${ }^{22}$ Capital expenditures, which are very small in this industry, are treated as part of partner earnings. Since partners are the residual claimants on law firms' assets, this treatment seems appropriate.
} 
Microdata Sample (PUMS). We report earnings distributions from the 1970, 1980, 1990, and 2000 PUMS in Table A1 in the Appendix. Although direct comparisons are impossible because the PUMS data come from different years than our data and because the PUMS data are top-coded, the distributions exhibit consistent patterns. In particular, the level and general time trend (in particular, low real earnings circa 1980-1982, higher real earnings before and after) in earnings are similar for the two series.

\subsection{Overhead}

The structure of law offices' overhead expenses exhibits a few interesting trends. In Table 4, we report coefficient estimates from regressions that relate overhead to observables. $^{23}$ The 1987 and 1992 estimates use PSOs; these are the estimates we use to generate partner earnings for these years. The 1977 and 1982 specifications use our main sample of partnerships and proprietorships (since we can estimate overhead directly for this sample for these years). The estimates indicate that while overhead is related to revenues in all years, the relationship between overhead and employment has tended to become stronger over time, especially for offices in very large cities and especially between 1987 and 1992. We suspect that this reflects, in part, changes in law offices' technology. From our earlier discussion, personal computers started to appear on lawyers' desks only in the late 1980s, and the early adopters of these and complementary hardware tended to be large, big-city law offices. If so, it would not be surprising to find that the relationship between overhead and employment tended to become stronger in the late 1980s and early 1990s, especially for offices in large cities.

The relationship between overhead, revenues, and employment bears on our estimation of equation (8). As noted above, part of the marginal cost of leverage consists of costs other than increases in associate pay, $c_{i}^{\prime}\left(n_{i}\right)$. We specify $c_{i}\left(n_{i}\right)$, as:

$$
\begin{aligned}
c_{i}\left(n_{i}\right) & =\left(x_{i} l_{i}+o h_{i}\right) / p_{i} \\
& =x_{i}\left(1+n_{i}\right)+o h_{i} / p_{i}
\end{aligned}
$$

\footnotetext{
${ }^{23}$ This summary table does not report all of the coefficients in these specifications, for example those on office's field shares and interactions between field shares and revenues. The full set of results for each year are available upon request from the authors.
} 
where $x_{i}$ is nonlawyer pay per lawyer, $l_{i}$ is the number of lawyers in office $i, o h_{i}$ is overhead at office $i$, and $p_{i}$ is the number of partners at office $i$. We assume that nonlawyer pay per lawyer is constant: hiring an additional associate implies a proportionate increase in the office's support staff. Thus:

$$
c_{i}^{\prime}\left(n_{i}\right)=x_{i}+o h_{i}^{\prime} / p_{i}
$$

From each partner in office $i$ 's perspective, an additional associate implies an increase in nonlawyer pay of $x_{i}$ and an increase in overhead of $o h_{i}^{\prime} / p_{i} . x_{i}$ is observed in the data. We use the coefficient estimates on employment in the results reported in Table 4 to construct an estimate of $o h_{i}^{\prime} / p_{i}$ for each office.

Finally, we note that our production function specification must account for the fact that the marginal benefits of leverage from a partner's perspective are not simply marginal revenues, but rather marginal revenues, net of the overhead associated with these revenues. We therefore adjust revenues for each office downward by $\left(1-\widehat{k_{i}}\right)$, where $\widehat{k}_{i}$ is the estimated derivative of overhead with respect to revenues for office $i$ implied by the estimates in Table 4 .

The production function specification is therefore:

$$
\ln \left[\frac{\left[R_{i}+w_{i} n_{i}+c_{i}\left(n_{i}\right)\right]}{\left(n_{i}+1\right)}\left(1-\widehat{k_{i}}\right)\right]-\ln \left(\widehat{w_{i}^{\prime}\left(n_{i}\right)} n_{i}+w_{i}+x_{i}+\widehat{o h_{i}^{\prime}} / p_{i}\right)=-\ln \theta+\ln \varepsilon_{i}
$$

where $\widehat{w_{i}^{\prime}\left(n_{i}\right)}$ is derived from our estimates of equation (9), presented below in Table 5 , and $\widehat{k}_{i}$ and $\widehat{o h_{i}^{\prime}}$ are derived from our estimates in Table $4 .^{24}$

\section{Results}

\subsection{Associate Earnings and Leverage}

Table 5 summarizes the coefficient estimates of equation (9); the specifications also include county fixed effects and "office class" dummies. The omitted field is "general practice." The patterns in the field controls are fairly consistent across years and

\footnotetext{
${ }^{24}$ Inserting predicted values on the left side of the specification introduces a source of bias to our estimates of $\theta$, once again because of Jensen's inequality (e.g., because $E\left[\ln \left(M C_{i}\right)\right]<\ln \left[E\left(M C_{i}\right)\right]$ ). As above we do not account for this bias directly in our estimation because we believe it to be small and consistent across time.
} 
show some expected patterns; for example, associate pay is relatively high at offices with a high share of corporate, tax law, or patent law specialists. Another notable pattern is that 1982 looks different than the other years for some specialized fields. Unlike other years, associate pay was not significantly higher at offices with high shares of banking, insurance, or negligence-defense specialists relative to those with high shares of general practitioners. This suggests that the returns to specialization were lower in this recessionary year than in other years, at least for some fields.

The coefficients of interest are those that relate associate earnings to associatepartner ratios; these are the polynomial coefficients at the top of the table. These coefficients are hard to interpret as presented; we therefore present additional evidence at the bottom of the table. There we report the difference between predicted percent difference of associate earnings at offices with associate-partner ratios of 1.5 and 0.5 ; the vast majority of lawyers work at offices with associate-partner ratios in this range. In general, the coefficient estimates imply that $w(n)$ differs across different classes of offices. The function is upward-sloping for all years for business nonlitigation offices, and the predicted increase in associate earnings when moving from an associate-partner ratio of 0.5 to 1.5 is $4 \%$ in 1977 and $10-15 \%$ in the other years. This pattern is similar, but muted, for litigation offices; the predicted increase is $4-7 \%$ in three of the years and slightly less than zero in the fourth. In contrast, $w(n)$ is essentially flat in three of the years (and downward-sloping in the other) for individual, non-litigation offices. The difference in $w(n)$ between this segment and the other segments may reflect that, from the perspective of partners in this segment of the industry, the quality and quantity of associates are more easily substitutable.

\subsection{The Benefits and Costs of Leverage}

We summarize some of the implications of these and our other estimates to date in Table 6. Here we depict how, from the perspective of partners, the marginal benefits and marginal costs have evolved over time. On average, partners worked in offices where revenues per lawyer were $\$ 195,000$ in 1977 ; this declined then increased during our sample period. The average benefit of leverage, which is this figure less the share of revenues that is overhead, exhibits a similar pattern. The average benefits of leverage for 1992 partners were about 30\% greater than those of 1977 partners. The marginal cost of leverage, averaged across partners in each year, 
exhibits a somewhat different pattern. It decreased slightly between 1977 and 1982, then increased substantially between 1982 and 1992. The marginal cost of leverage for 1992 partners was about 50\% greater than that of 1977 partners. As noted above, the coordination cost of hierarchies is identified by the ratio between the marginal cost and average benefit of leverage, evaluated at equilibrium quantities. Table 6, which indicates that the marginal cost increased relative to the average benefit of leverage between 1977 and 1992, presages our finding that the coordination cost of leverage has declined over time.

The right part of Table 6 depicts how the composition of marginal costs have evolved. Associate pay has fluctuated, but is a smaller share of the marginal cost of leverage over time, declining from $53 \%$ to $45 \%$. Overhead, in contrast, increases both in its magnitude and its share of the marginal cost of leverage, rising from a negligible share in 1977 to $13 \%$ of the average partner's marginal costs in 1992 . The marginal price of leverage, which reflects the possibility that hiring more associates means hiring better associates, is a small, though increasing, part of the marginal cost of leverage for the average partner in each year. This low average masks considerable heterogeneity across offices, but cases where the marginal price of leverage exceeds $\$ 10,000$ are rare simply because $n$ is low in this industry. While it is important to account for these other components, the payroll-related costs of an additional associate make up most of the marginal cost of leverage for most partners.

\subsection{The Coordination Costs of Hierarchies}

Table 7 presents our estimates of equation (10), and the average predicted value of $\theta$ that these coefficient estimates imply. From the bottom of the table, on average, $\theta$ steadily increased between 1977 to 1992 from 0.57 to 0.71 . From the perspective of the average partner, hiring one's first associate increased the time that the (now 2-person) team would spend in production by about one-half in 1977, but by about two-thirds in 1992. The real team size after hiring an associate would have increased from 1 to 2 individuals in both periods; the effective team size would have increased from 1 to $2^{.57}=1.48$ individuals in 1977 and to $2^{.71}=1.63$ in 1992 , about $30 \%$ more. The fact that the coordination costs associated with hierarchical production declined steadily during this time is interesting, because it indicates that the overall decline cannot be solely attributed to technological changes that took place only in some of 
these subperiods. In particular, this pattern cannot be solely due to the diffusion of personal computers within law firms, which was important only in the final subperiod in our sample, 1987-1992. This pattern is consistent with the hypothesis that the steady diffusion of a series of new applications lowered coordination costs during this period, starting with computer-aided legal research in the late 1970s.

Table 8 provides evidence on the hypothesis that changes in $\theta$ reflect changes in the slope of the demand curves that partners face rather than coordination costs. Here we report average predicted values of $\theta$, by year, for cells that are defined by the number of partners in the office and the employment size of the county in which the office is located. These predicted values are generated from production function specifications that include dummy variables for each of these cells. ${ }^{25}$ The general pattern that this table reveals is that $\theta$ increased during this period in all of our office size*market size cells, though it tended to increase somewhat more for smaller offices than larger offices. The latter implies a convergence of sorts; the figures in the first column indicate that $\theta$ was higher for larger offices than smaller offices in 1977, but varied little with office size in 1992. The trends across market size and office size*market size categories do not support the hypothesis that changes in $\theta$ over time reflect changes in competition that partners face. From the top panel, the changes in $\theta$ for offices in small markets were no larger than changes in $\theta$ for offices in large markets; it does not appear that overall changes in $\theta$ reflect that partners in small market firms faced increasing competition over time, since this would imply that $\theta$ should increase more for small market offices than large market offices. Changes in $\theta$ for small offices in large markets were, if anything, larger than changes in $\theta$ for large offices in large markets. Partners in small offices in large markets likely faced strong competition throughout this period, but $\theta$ decreased by more for such partners than for their large office counterparts. We therefore conclude that the changes in $\theta$ that we uncover are likely to reflect changes in coordination costs during this period, not changes in competition. This is not particularly surprising; as described earlier, most lawyers likely faced strong competition from other lawyers throughout our sample period.

\footnotetext{
${ }^{25}$ We do not report the coefficient estimates from these specifications for brevity; they are available upon request from the authors.
} 


\subsection{Evidence on Coordination Costs and Lexis}

We investigate whether the decreases in coordination costs we uncover above are related to the diffusion of computer-aided legal research by exploiting the fact that state materials were added to Lexis libraries gradually, and some states' materials were added earlier than others. Lexis was thus more valuable for lawyers in some states than others during certain periods. We therefore investigate whether patterns in coordination costs are correlated with the timing of the availability of state materials: did $\theta$ decrease earlier in states where state materials were available earlier? In particular, we examine whether $\theta$ was systematically lower in 1982, but not in 1977 or 1987, in states where materials were available early than late.

We obtained data on the timing of Lexis availability by examining documents from the files of Robert Asman, President of the Ohio State Bar Association Automated Research. ${ }^{26}$ A series of documents from the mid-1970s-early 1980s, including contracts and promotional materials, allow us to observe what was available on Lexis at different points in time. The state materials on Lexis during this period typically included the decisions of the states' Supreme Court and important Courts of Appeals. Lexis would typically try to make available these decisions for at least the previous 15-20 years (going back to somewhere in the 1950s or 1960s); once this was achieved, it would move on to other states. Lexis generally added larger states earlier, as potential demand was greater in these states.

We were able to obtain availability at several points in time; we count a state as having availability if state Supreme Court decisions are available for at least the previous ten years. By June 1974, materials were available for Missouri, Ohio, and New York. By November 1976, they were available for eight more states: California, Delaware, Florida, Illinois, Kansas, Massachusetts, Pennsylvania, and Texas. We will refer to these 11 states as the "early" states and the rest as the "late" states. ${ }^{27}$ Eleven more states were available by August 1979; all 50 states were available by 1982.

The top panel of Table 9 provides some initial results from this exercise. The variable "early Lexis state" equals one if the law office is located in an early state

\footnotetext{
${ }^{26}$ These files are maintained in the Case Western University Law Library; thanks to Kathleen Carrick for providing us access to them.

${ }^{27}$ We experimented with dividing states into four categories rather than two, and found that results were similar for the two "early" categories and for the two "late" ones; we therefore combined them.
} 
and zero if it is located in a late state. The coefficient on this variable is negative and significant in each of our sample years; however, there is no evidence that it is particularly large in 1982 relative to the surrounding years. These regressions thus provide no support for the proposition that declines in coordination costs are related to the availability of Lexis materials.

The bottom panel contains some more detailed results that distinguish between large and small law offices; although Lexis tried to market its service to small law offices (through the availability of public terminals priced on a per use basis), it is clear that most adoption of the service was by larger law offices. We therefore create a dummy that equals one if the office has at least 10 partners and zero otherwise, and include interactions between this variable and the "early" dummy to investigate whether there is a difference in $\theta$ between large law offices in early and late states in 1982 but not before or after. Table 9 provides evidence that this is indeed the case. The coefficient on the "early Lexis state*at least 10 partners" interaction is negative and significant in 1982, but close to zero and not statistically significant in 1977 or 1987. Looking across large law offices, coordination costs declined in early states relative to late states between 1977 and 1982; late states then caught up between 1982 and 1987. There is thus some evidence that some of the decreases in coordination costs in Table 7 are related to the diffusion of computer-aided legal research.

While this pattern is interesting, it is important to recognize that the evidence that it provides is not conclusive. The "early" states tend to be states that contain the cities with the most lawyers in the country: New York City, Los Angeles, Chicago, etc. Absent detailed firm- or office-level data on adoption, it is unlikely that we can provide evidence against alternative hypotheses in which other factors lowered coordination costs for large law offices in states with large cities in 1982 but not before or after. ${ }^{28}$ We see the results in Table 9 as suggestive of connections between the availability of new information technology and coordination costs (and therefore to increases in lawyers' earnings inequality), but more detailed data are necessary to establish these connections definitively.

\footnotetext{
${ }^{28}$ We have, however, examined whether this pattern is merely a big city effect by investigating whether it holds when dummying out offices in New York, Los Angeles, Chicago, Dallas, Houston, and San Francisco. The pattern persists even when doing so.
} 


\section{5 "Hierarchy-Free" Earnings Distributions}

In this section we construct and report estimates of $R_{i}\left(z_{m i}, 0\right)$ : what lawyers would earn, if they were unleveraged. We refer to the distribution of $R_{i}\left(z_{m i}, 0\right)$ across lawyers as the "hierarchy-free" earnings distribution, and compare it to lawyers' actual earnings distribution to infer the effect of hierarchical organization on earnings inequality. We emphasize that our analysis on this front is a partial equilibrium analysis, because this counterfactual holds constant the distribution of lawyers' skills as well as the match between clients and law firms. If lawyers, in fact, did not organize hierarchically, this would affect lawyers' investments in skills and the match between clients and lawyers.

We estimate "hierarchy-free" earnings distributions in the following way. For unleveraged partners, estimating $R_{i}\left(z_{m i}, 0\right)$ is simple: these lawyers' "hierarchy-free" earnings equal their actual earnings. For leveraged partners, $R_{i}\left(z_{m i}, 0\right)=\widehat{z}_{m i}-c_{i}(0)$, where $\widehat{z}_{m i}=T R_{i} /\left(n_{i}+1\right)^{\widehat{\theta}_{i}}$ and $c_{i}(0)=x_{i}+\widehat{o h}_{i} / p_{i}$. One can think of the first of these components, $\widehat{z}_{m i}$, as the market value of the partners' (unleveraged) time; crosslawyer differences in this component would reflect, in part, differences in lawyers' skill but not differences in organization. The second of these components is what lawyers' costs would be if they were unleveraged; these costs include the cost of nonlawyer support staff and overhead. For associates, we assume that $R_{i}\left(z_{m i}, 0\right)=w_{i}$ : their earnings if unleveraged equal what they earn as associates. Revealed preference arguments imply that associates' actual earnings should overstate their "hierarchy-free" earnings; in a model where individuals choose where to work to maximized their income, individuals who choose to be associates should earn more as associates than they would as unleveraged partners. Our estimates of "hierarchy-free earnings distributions" thus probably overstate lawyers' hierarchy-free earnings, especially below the median. This assumption will have a minimal effect on our main analysis, however, which focuses on quantiles at or above the median. It is important to include associates in the analysis of earnings distributions, but overstating their "hierarchyfree" earnings slightly will not affect our analysis as long as these individuals tend to be below the median in the "hierarchy-free" earnings distributions that we compute.

Table 10 reports quantiles of the hierarchy-free earnings distributions in each of our years. This table is analogous to the earnings distributions we reported in Table 1, which we reproduce in the top panel of this table for comparison. The most 
important finding in this table is that inequality increases over time in the "hierarchyfree" earnings distribution, just like it does in the realized earnings distribution. The ratio between the 90th and 50th quantile increased from 2.4 to 2.8, and that between the 95th and 50th increased from 3.0 to 3.6 between 1977 and 1992 . This finding indicates that increases in earnings inequality over time are not solely due to the degree to which lawyers are leveraged; even taking out the effect of increases in leverage, inequality increased substantially among lawyers above the median.

Before continuing, we note that we have characterized this result carefully. The results in Table 10 do not rule out the possibility that all of the increase in earnings inequality could be due to decreases in the coordination costs associated with hierarchical production. If increases in $\theta$ lead highly-skilled lawyers to accumulate more skill, this would be reflected by changes the hierarchy-free earnings distribution. The "pure leverage" effect to which we refer above is a lower bound of the impact of changes in $\theta$ on earnings inequality, because it does not include the effect of human capital investments that are responses to these changes.

Another finding in Table 10 echoes Garicano and Hubbard (2007a): hierarchical production amplifies earnings inequality. All of the earnings quantile ratios in the top panel are greater than those in the bottom panel, and the differences between the top and bottom panels are greater when the ratios involve higher quantiles. Our previous work showed this for 1992; here we show that similar conclusions hold for other years.

\subsection{Organizational Changes and Increases in Earnings In- equality}

Table 11 analyzes the extent to which increases in organizational leverage contributed to increases in earnings inequality between 1977 and 1992 through a decomposition of changes in the quantile ratios. The top panel uses law offices in all segments. The first column reports that the ratio between the 90th percentile and median earnings increased by 0.20 log points; in contrast, this ratio increased by 0.16 log points when using our estimates of the hierarchy free earnings distributions in these years. The difference between the two, here called the "residual change in earnings inequality," depicts the change in earnings ratios that is attributable to changes in lawyers' leverage. The final row reports this as a share of the change in the earnings quantile ratio. 
From the table, we estimate that $17 \%$ of the change in the 90 th/50th percentile ratio during this time is due to changes in lawyers' leverage. This figure is greater when examining ratios that focus more on the upper tail: we estimate that $38 \%$ of the increase in the 95 th/50th percentile ratio, and $69 \%$ of the increase in the 95th/90th percentile ratio, is due to changes in lawyers' hierarchical organization.

Increases in organizational leverage thus explain the majority of the increase in earnings inequality among very top lawyers. They explain a substantial, but moderate amount of the increase in inequality between lawyers at the top of the distribution and the median lawyer. Most of the earnings inequality increase between top lawyers and the median lawyer is accounted for instead by differential changes in the market value of lawyers' time. Some of these differential changes may have organizational roots. Declines in the coordination costs of hierarchical production may have led the most skilled lawyers to increase their human capital disproportionately relative to other lawyers. These numbers are therefore likely to be a lower bound on the effect of declines in coordination costs on earnings inequality during this time.

The bottom panel reports a similar analysis, conducted separately for lawyers in "business, non-litigation," "litigation," and "individual, non-litigation" offices. The qualitative results for lawyers in "business, non-litigation" and "litigation" offices are similar to each other and to the results in the top panel: changes in leverage explain a large share of the increase in inequality among lawyers in the upper tail of the distribution, and a moderate share of the increase in inequality between these lawyers and the median lawyer. The effect of changes in leverage on earnings inequality among top lawyers is particularly pronounced among lawyers in "business, non-litigation" offices (e.g., offices that do transactional work for business clients but not litigation): over three-quarters of the change in the $95 \mathrm{th} / 90$ th percentile earnings ratio is accounted for by changes in leverage, but none of the increase in the 90th/50th ratio. The results for lawyers in "individual, non-litigation" offices differ from those in other offices. Inequality increased substantially among lawyers in this segment during this time, especially comparing lawyers in the upper tail to those in the middle. But we find little evidence that this increase reflects changes in leverage: changes in the "estimated earnings, absent hierarchical production" ratios are similar in magnitude to changes in the estimated earnings ratios. 


\subsection{Productivity Decompositions}

Our final set of results investigate changes in lawyers' productivity between 197792 , as measured by revenues per lawyer, in light of the decline in coordination costs that took place during this time. Our analytic framework, and in particular the hierarchical production function that we propose, facilitates this analysis by positing that output is simply the product of skill and time: partner skill multiplied by the time lawyers in the office spend in production.

Dividing both sides of equation (1) by $n_{i}+1$, we obtain an expression for revenues per lawyer at office $i$ :

$$
y_{i} /\left(n_{i}+1\right)=z_{m i}\left(n_{i}+1\right)^{\theta-1}=z_{m i} s_{i}
$$

where $s_{i}=\left(n_{i}+1\right)^{\theta-1}$, the share of lawyers' time that is spent directly in production. Office-level productivity increases therefore can either reflect increases in partner skill or increases in lawyers' time-efficiency.

Average revenues per lawyer across all offices is therefore:

$$
\begin{aligned}
\overline{y_{i} /\left(n_{i}+1\right)} & =\overline{z_{m i} s_{i}} \\
& =\overline{z_{m}} \bar{s}+\operatorname{cov}\left(z_{m i}, s_{i}\right)
\end{aligned}
$$

where the covariance and means are calculated using the number of lawyers in the office as weights. Our analytic framework and results imply that the covariance term should be negative: more skilled partners are more leveraged, but if $\theta<1$ this lowers the share of time that lawyers spend directly in production. One can therefore decompose changes in average revenues per lawyer in the following way:

$$
\Delta \overline{y_{i} /\left(n_{i}+1\right)}=\Delta \overline{z_{m}} \overline{s_{t}}+\Delta \bar{s} \overline{z_{m, t-1}}+\Delta \operatorname{cov}\left(z_{m i}, s_{i}\right)
$$

The first term is the change in the average value of skill that is applied to lawyers' time, holding lawyers' time efficiency constant. The second is the change in the share of lawyers' time spent in production, holding the average value of skill constant. The third is the change in the covariance between skill and time efficiency.

We report our results in Table 12. Real revenues per lawyer increased by $\$ 46,000$ between 1977 and 1992; this measure of productivity therefore increased by just over $25 \%$ during our sample period. The decomposition indicates that none of the productivity increase is accounted for by increases in lawyers' time efficiency. Although 
coordination costs decreased during this period, lawyers responded to this by increasing leverage in a way that left lawyers' average time efficiency unchanged. In contrast, all of the productivity increase is accounted for by increases in the average value of skill that is applied to lawyers' time. Even though the direct effect of reductions in coordination costs are to increase lawyers' time efficiency, lawyers' aggregate response to these reductions ultimately exploited the input that is a source of increasing returns rather than the input that is not; skill rather than time.

\section{Conclusion}

Labor economists have long been concerned with the mechanisms behind the increases in earnings inequality since the late 1970s. ${ }^{29}$ The literature has concluded that the phenomenon is primarily the consequence of changes in the demand for skill rather than changes in the supply of skill. It has also tentatively concluded that technological changes, rather than trade, are the likely culprits. Recently, some authors have argued that scale effects along the lines of those examined in Rosen $(1981,1982)$ have disproportionately affected earnings at the very top of the distribution by allowing individuals to exploit better increasing returns associated with their skill. ${ }^{30}$

In this paper we analyze data from U.S. lawyers between 1977-1992 and provide evidence on how changes in the ability of individuals to exploit increasing returns associated with their skill have contributed to earnings inequality in this industry. We find that the coordination costs associated with hierarchical production diminished significantly during this period, and that increases in associate-partner ratios during this time account for about two-thirds of the increase in earnings inequality among very top lawyers, but a much smaller share of the increase in earnings inequality between top lawyers and other lawyers. Preliminary evidence indicates that these changes in organizational costs may be related to availability of computer-aided legal research services such as Lexis. However, more detailed data are necessary to establish this firmly and to investigate the particular paths through which declines in various classes of information costs have affected organization and inequality in this

\footnotetext{
${ }^{29}$ See notably Katz and Murphy (1992).

${ }^{30}$ Garicano and Rossi-Hasberg (2006) show that improvements in communication technology expand effective team size and increase the reach of hierarchy; Gabaix and Landier (2008) show that changes in firm size (as given by market capitalization) can account for most of the recent expansion of executive pay among very large firms.
} 
industry.

We see this paper as contributing to the understanding of the organizational underpinnings of changes in labor market outcomes. Our evidence highlights that changes in external and internal labor markets are closely related; understanding changes in what have traditionally been considered external labor market outcomes is likely to require studying how the demand and organization of skill and time changes inside firms. While law offices are an unusually clean laboratory, given offices' small size and comparable organizational structures, future studies in other industries with more organizationally complex firms should allow for further insights, in particular by allowing for an analysis of changes in the number of hierarchical layers in firms, which we could not measure in our data as most law firms (and our data) distinguish only between partners and associates.

\section{Appendix}

Proof. Recall that the equilibrium construction above results in two equations in two unknowns. First, solving the market clearing condition (5), yields $m(z)=\phi(z)+C$ for some increasing and continuous function $\phi($.$) . We eliminate the constant by$ substituting $m\left(z_{1}\right)=\bar{z}$, so that we have $C=\bar{z}-\phi\left(z_{1}\right)$, and thus $m(z)=\phi(z)+\bar{z}-$ $\phi\left(z_{1}\right)$. We then substitute the other threshold matching condition $m(\underline{z})=z_{2}$, yielding $z_{2}+\phi\left(z_{1}\right)=\phi(\underline{z})+\bar{z}$, which contains only two unknowns, the thresholds $z_{1}$ and $z_{2}$. Second, indifference of the marginal manager implies $R\left(z_{2}\right)=z_{2}$. The system of equations we must characterize can thus be written as:

$$
\begin{aligned}
z_{2}+\phi\left(z_{1}\right) & =\phi(\underline{z})+\bar{z} \\
z_{2}(n(\underline{z})+1)^{\theta}-n(\underline{z}) w\left(\underline{z}, z_{1}\right) & =z_{2}
\end{aligned}
$$

where $w\left(\underline{z}, z_{1}\right)$ is a function of $z_{1}$ but not of $z_{2}$ (to see this, note that $w(z)$ is obtained by substituting $m\left(z_{w}\right)=\phi\left(z_{w}\right)+\bar{z}-\phi\left(z_{1}\right)$ for $z_{m}$ in (3) together with $w\left(z_{1}\right)=z_{1}$; none of these are functions of $z_{2}$ ).

Consider first (11). Since $\phi^{\prime}>0,(11)$ defines a market clearing function $z_{2}^{m}\left(z_{1}\right)$ with $d z_{2}^{m} / d z_{1}<0$. Intuitively, if more workers are used ( $z_{1}$ increases), more managers are needed $\left(z_{2}\right.$ decreases). Second, define $\underline{w}=w\left(\underline{z}, z_{1}\right)$, and notice that (12) implies 
$z_{2}^{\prime}(\underline{w})>0$. Since $d w\left(\underline{z}, z_{1}\right) / d z_{1}>0,{ }^{31}(12)$ implies a second function $z_{2}^{r}\left(z_{1}\right)$ with $d z_{2}^{r} / d z_{1}>0$. Intuitively, suppose $z_{1}$ were to increase. Since the wage function $w\left(\underline{z}, z_{1}\right)$ is increasing in $z_{1}$, the wage paid by the marginal manager would increase. This marginal manager becomes better off unleveraged, and $z_{2}$ therefore increases. The intersection of the curves $z_{2}^{m}$ and $z_{2}^{r}$, if it exists, thus uniquely results in an equilibrium $z_{1}$ and $z_{2}$. Moreover, inspection of the system above shows that (11) does not depend on $\theta$, while the rent function $R\left(z_{2}, \underline{z}, \underline{w}\right)$ is increasing in $\theta$ (by the envelope theorem). Thus an increase in $\theta$ shifts $z_{2}^{r}\left(z_{1}\right)$ to the right and results in an increase in $z_{1}$ and a decrease in $z_{2}$.

Proposition (2). 1 . The changes in $z_{1}$ and $z_{2}$ are shown in Lemma 1 above. The change in the span $n\left(z_{w}\left(z_{m}\right)\right)$ follows straighforwardly from the change in the matching function $m(z)=\phi(z)+\bar{z}-\phi\left(z_{1}\right)$ :

$$
\frac{d m(z)}{d \theta}=-\phi^{\prime}\left(z_{1}\right) \frac{d z_{1}}{d \theta}<0
$$

That is, workers of a given skill are assigned less-skilled managers. Inverting the function $m($.$) we have that$

$$
\frac{d z_{w}\left(z_{m}\right)}{d \theta}>0
$$

Managers of a given skill are assigned more-skilled workers. It follows straighforwardly that $d n / d \theta=n^{\prime} \frac{d z_{w}\left(z_{m}\right)}{d \theta}>0$. Managers of a given skill are assigned better workers and manage more of them. To see that the average span for the economy increases, note simply that the lowest span is unchanged by the entry of new managers, since workers with skill $\underline{z}$ are always matched in equilibrium, and the span of teams involving these workers, $n(\underline{z})$, is limited by their skill.

2. To characterize $\frac{d\left[R(\bar{z})-R\left(z_{2}\right)\right]}{d \theta}$ we proceed in two steps. First consider the change in the slope of the rent function $d R / d z$.

$$
\frac{d^{2} R}{d \theta d z_{m}}=\left(n\left(z_{w}\right)+1\right)^{\theta} \log \left[\left(n\left(z_{w}\right)+1\right]^{\theta}+\theta\left(n\left(z_{w}\right)+1\right)^{\theta-1} n^{\prime}\left(z_{w}\right) \frac{d z_{w}\left(z_{m}\right)}{d \theta}\right.
$$

The first term is the partial equilibrium impact (that is, holding the matching and spans constant) $\left.\frac{d^{2} R}{d \theta d z_{m}}\right|_{m(z)}=\frac{d(n+1)^{\theta}}{d \theta}>0$. Intuitively, since managers leverage their talent over a team of workers, decreases in coordination costs increase the return

\footnotetext{
${ }^{31}$ The calculation containing this derivative is a bit involved and suppressed here; the Mathematica file containing it is available from the authors.
} 
to managerial talent. The second effect is the general equilibrium effect due to the change in matching; by the argument in the proof of the first part of the proposition, it is also positive. Thus the slope $d R / d z$ is everywhere greater.

Finally, $\frac{d\left[R(\bar{z})-R\left(z_{2}\right)\right]}{d \theta}=\frac{\left.d\left[R\left(\bar{z}, z_{1}, \theta\right)\right)-z_{2}\right]}{d \theta}=\frac{d R}{d \theta}+\frac{d R}{d z_{1}} \frac{d z_{1}}{d \theta}-\frac{d z_{2}}{d \theta}>0$. The first term is the direct effect of $\theta$, and is positive by the envelope theorem. The second is a general equilibrium/matching effect. Managers are matching with better workers, which leads this term to be positive since $d z_{1} / d \theta>0$ by Lemma 1 . The last term is also a general equilibrium effect; $\frac{d z_{2}}{d \theta}<0$, as Lemma 1 implies that decreases in coordination costs lead the the earnings of the marginal manager to be lower (as more agents become managers).

\section{References}

Abel, Richard L. American Lawyers. Oxford University Press, New York, 1989.

Autor, David H. and Lawrence F. Katz, "Changes in the Wage Structure and Earnings Inequality," Harvard University, 1998.

Autor, David H., Lawrence F. Katz, and Melissa S. Kearney. "Trends in U.S. Wage Inequality: Revising the Revisionists," MIT, 2007.

Card, David and John E. DiNardo. "Skill-Biased Technological Change and Rising Wage Inequality: Some Problems and Puzzles," Journal of Labor Economics, Vol. 20, No. 4 (October 2002), 733-83.

Epple, Dennis. "Hedonic Prices and Implicit Markets: Estimating Demand and Supply Functions for Differentiated Products." Journal of Political Economy, Vol. 95, No. 1 (February 1987): 59-80.

Gabaix, Xavier and Augustin Landier. "Why Has CEO Pay Increased So Much?" Quarterly Journal of Economics, Vol. 123, No. 1 (February 2008): 49-100.

Garicano, Luis. "Hierarchies and the Organization of Knowledge in Production." Journal of Political Economy, Vol. 108, No. 5 (October 2000): 874-904.

Garicano, Luis and Thomas N. Hubbard. "The Return to Knowledge Hierarchies." NBER Working Paper 12815, January 2007a. 
Garicano, Luis and Thomas N. Hubbard. "Managerial Leverage Is Limited by the Extent of the Market: Hierarchies, Specialization, and the Utilization of Lawyers' Human Capital." Journal of Law and Economics, Vol. 50, No. 1 (February 2007b), 1-44.

Garicano, Luis and Esteban Rossi-Hansberg. "Organization and Inequality in a Knowledge Economy." Quarterly Journal of Economics, No. 121, Vol. 4 (November 2006), $1383-1436$.

Kaplan, Steven N. and Joshua Rauh. "Wall Street and Main Street: What Contributes to the Rise in the Highest Incomes?" Mimeo, University of Chicago, July 2007.

Katz, Lawrence F. and Kevin M. Murphy. "Changes in Relative Wages, 1963-87: Supply and Demand Factors," Quarterly Journal of Economics, Vol. 107, No. 1 (February 1992), 35-78.

Lucas, Robert E.. "On the Size Distribution of Business Firms," Bell Journal of Economics, Vol. 9, No. 2 (Autumn 1978): 508-523.

Rosen, Sherwin. "Hedonic Prices and Implicit Markets: Product Differentiation in Pure Competition." Journal of Political Economy, Vol. 82, No. 1 (January 1974): 34-55.

Rajan, Raghuram G. and Julie Wulf. "The Flattening Firm: Evidence on the Changing Nature of Firm Hierarchies from Panel Data." Review of Economics and Statistics, Vol. 88 , No. 4 (November 2006), 759-773.

Rosen, Sherwin. "Hedonic Prices and Implicit Markets: Product Differentiation in Pure Competition." Journal of Political Economy, Vol. 82, No. 1 (January 1974): 34-55.

Rosen, Sherwin. "The Economics of Superstars" The American Economic Review, Vol. 71, No. 5. (Dec., 1981): 845-858.

Rosen, Sherwin. "Authority and the Distribution of Earnings." Bell Journal of Economics, Vol. 13, No. 2 (Autumn 1982): 311-323.

Staudt, Ronald and Rosemary Shiels. "The End of the Beginning: The Computerization of the Practice of Law in Large Firms." American Lawyer, Special Supplement, May 1994.

Tervio, Marko. "The Difference that CEOs Make: An Assignment Model Approach." American Economic Review, Vol. 98, No. 3 (June 2008): 642-668. 


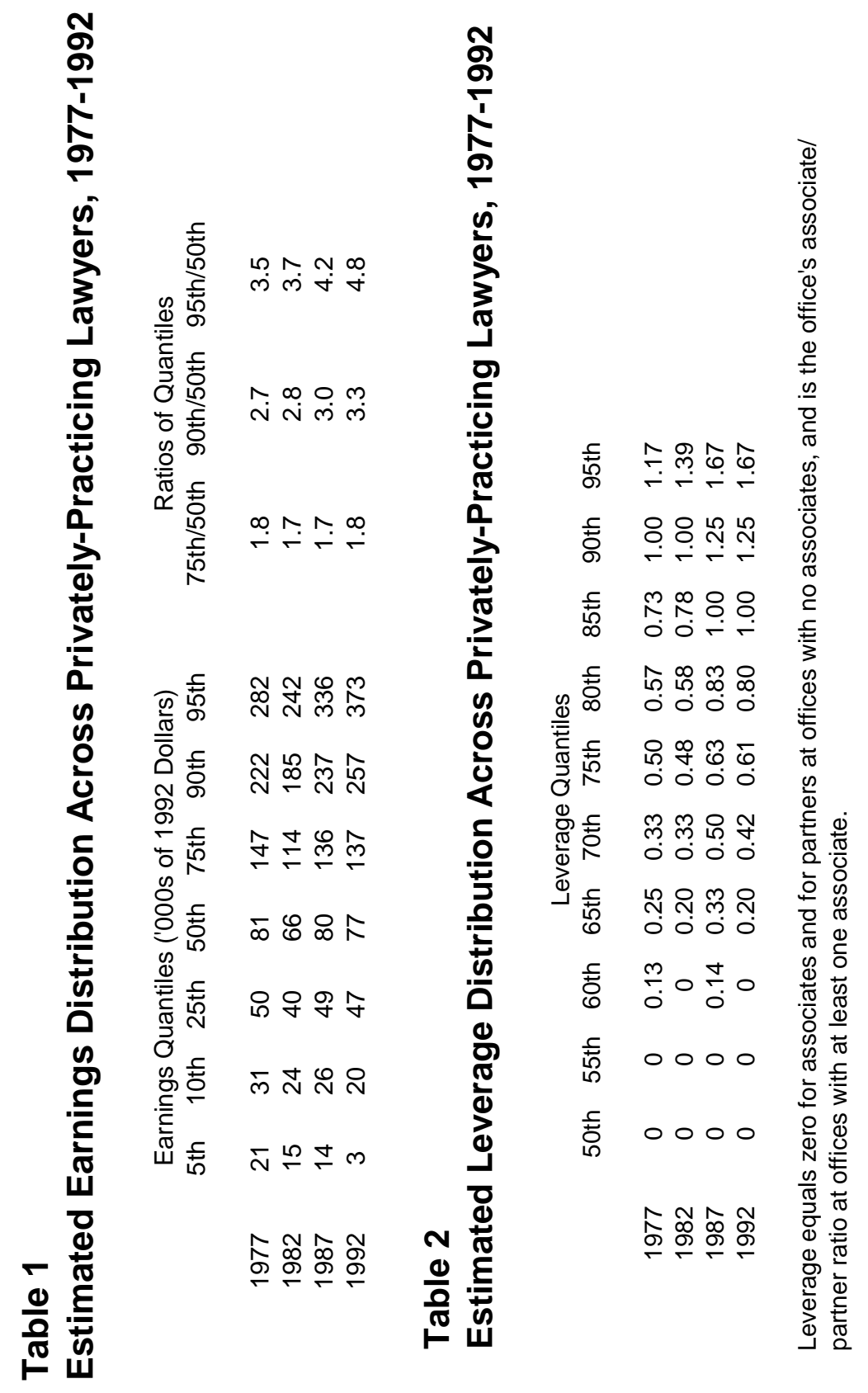




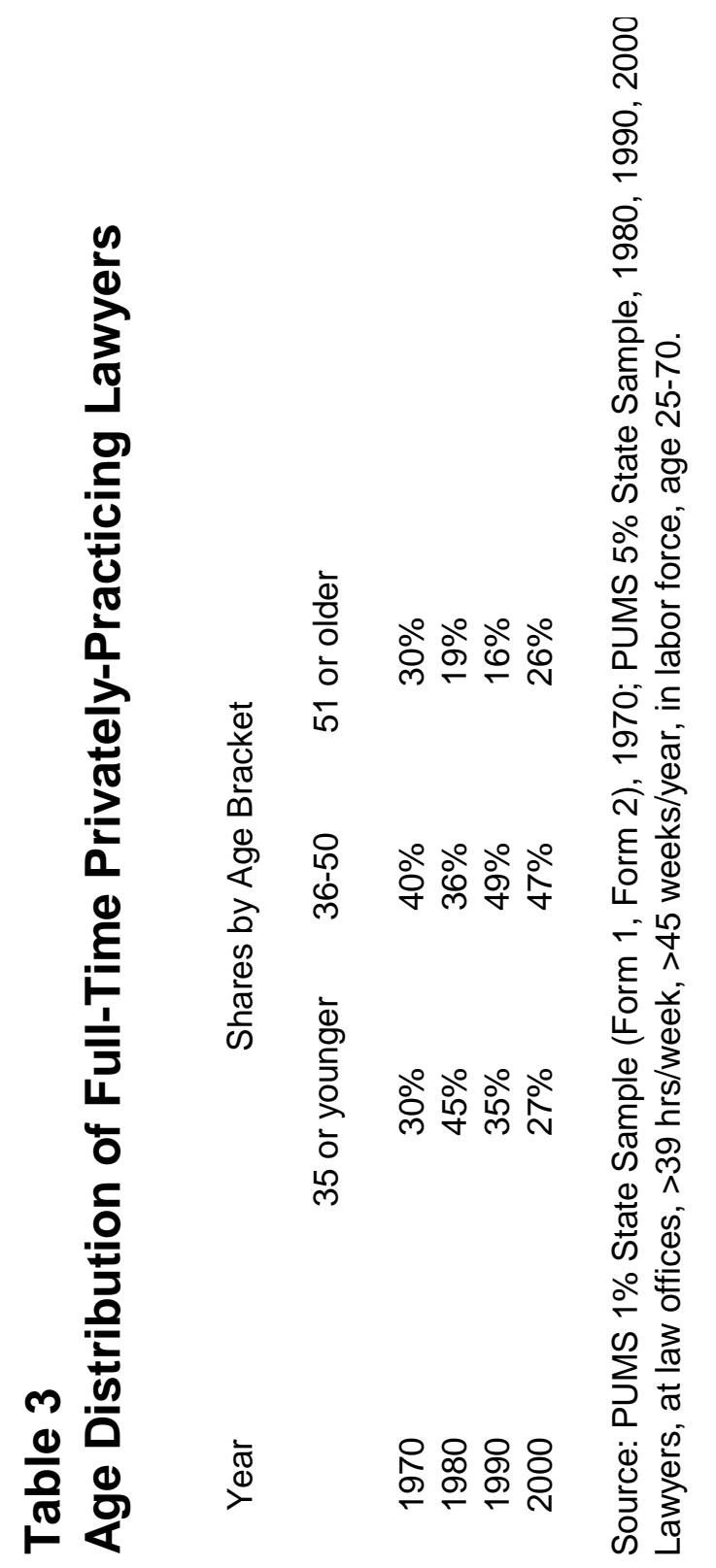




\section{Table 4}

\section{Overhead, Employment, and Revenues}

Offices That Are Legally Organized As Partnerships or Proprietorships for 1977 and 1982, As PSOs for 1987 and 1992.

Dependent Variable: (Expenses - 1.15*Payroll) for 1977, 1982; (Revenues - 1.15*Payroll) for 1987, 1992

$\begin{array}{lcccc} & 1977 & 1982 & 1987 & 1992 \\ \text { C } & \mathbf{4 . 2 3 7} & 0.960 & \mathbf{2 2 . 6 7 2} & \mathbf{2 8 . 5 0 8} \\ & \mathbf{( 0 . 9 2 8 )} & (1.211) & \mathbf{( 3 . 7 9 5 )} & \mathbf{( 2 . 5 0 8 )} \\ \text { Employment } & & & & \\ & 0.407 & 0.014 & 0.475 & \mathbf{2 . 8 6 4} \\ & (0.368) & (0.605) & (0.802) & \mathbf{( 0 . 6 0 3 )}\end{array}$

Market Size Employment Interactions

$20 \mathrm{~K}-100 K^{\star}$ Employment

$\begin{array}{llll}-0.958 & -0.740 & -0.098 & 0.796\end{array}$

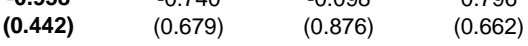

$100 \mathrm{~K}-200 K^{\star}$ Employment

$\begin{array}{llll}-0.532 & 1.429 & 0.483 & 0.984\end{array}$

200K-400KEmployment

$(0.516)$

$(0.773)$

(0.923)

(0.701)

$-0.236$

$-0.333$

0.551

2.139

400K-1MEmployment

0.903

(0.736)

(0.866)

(0.647)

(0.451)

$-0.352$

2.433

2.279

More than $1 \mathrm{M}^{\star}$ Employment

2.616

(0.766)

(0.858)

(0.657)

(0.539)

$$
1.473
$$

4.856

(1.008)

13.896

(0.735)

Revenues Quadratic

Revenues

Revenues^2

Market Size Dummies

$20 \mathrm{~K}-100 \mathrm{~K}$

100K-200K

200K-400K

$400 \mathrm{~K}-1 \mathrm{M}$

More than $1 \mathrm{M}$

N

R-Squared
0.219

(0.004)

0.262

(0.007)

0.279

(0.009)

-9.16E-06

(1.77E-06)

$-4.81 \mathrm{E}-06$ (2.75E-06)

$-5.88 \mathrm{E}-06$

(3.39E-06)

0.213

(0.007)

$-7.61 \mathrm{E}-06$

(1.80E-06)

$\begin{array}{lcccc}\text { More than } 1 \mathrm{M} & \mathbf{9 . 8 6 5} & \mathbf{1 1 . 1 3 1} & \mathbf{- 1 5 . 3 0 2} & \mathbf{- 2 0 . 1 8 1} \\ & \mathbf{( 1 . 3 0 8 )} & \mathbf{( 1 . 9 8 0 )} & \mathbf{( 4 . 2 7 3 )} & \mathbf{( 3 . 0 3 2 )} \\ \mathrm{N} & 12043 & 4883 & 10647 & 10438 \\ \text { R-Squared } & 0.59 & 0.59 & 0.53 & 0.70\end{array}$

Specification also includes the (uninteracted) field shares of lawyers in the office, and interactions between the field shares and the revenues quadratic. Omitted field category is "share(general practitioner)."

Market size dummies are defined in terms of total 1992 employment in the county in which the office is located.

Employment is the total number of individuals (lawyers and non-lawyers) working in the office, minus 2.

Bold indicates rejection of the hypothesis $b=0$ using a one-tailed t-test of size 0.05 . 
Table 5

Wage-Leverage Surface Estimates, 1977-1992

Partnerships and Proprietorships With At Least One Associate

Coefficient Estimates

Associates/Partner -- "Business, Non-Litigation Offices"

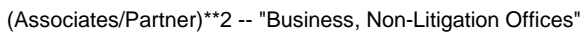

Associates/Partner -- "Litigation Offices"

0.085

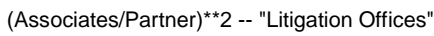

Associates/Partner -- "Individual, Non-Litigation Offices"

(Associates/Partner) ${ }^{\star \star 2 ~--~ " I n d i v i d u a l, ~ N o n-L i t i g a t i o n ~ O f f i c e s " ~}$

0.020

Share(Banking Law Specialist)

Share(Corporate Law Specialist)

0.387

(0.051)

1982

1987

1992

Share(Insurance Law Specialist)

$\mathbf{0 . 1 9 2}-0.036$

(0.062)

Share(Negligence-Defense Specialist)

0.182

(0.056)

(0.053)

0.200

(0.058)

0.146

$-0.035$

(0.016)

$-0.029$

(0.016)

$-0.116$

(0.062)

0.067

(0.054)

0.048

(0.017)

$-0.104$

(0.065)

0.044

(0.018)

$-0.020$

(0.078)

0.318

(0.061)

$-0.007$

(0.014)

$-0.215$

(0.080)

0.053

(0.025)

0.234

(0.072)

$(0.013)$

0.029

(0.043)

0.007

(0.010)

0.002

(0.060)

$-0.026$

(0.016)

0.579

(0.061)

0.193
(0.062)

0.675

0.226

(0.058)

(0.066)

(0.070)

0.245

(0.061)

(0.046)

0.030

(0.067)

Share(Patent Law Specialist)

$(0.047)$

(0.051)

0.404

(0.066)

$(0.048)$

0.413

0.037

0.250

(0.099)

(0.129)

(0.055)

Share(Government Law Specialist)

Share(Environmental Law Specialist)

Share(Real Estate Law Specialist)

0.088

(0.053)

0.159

(0.065)

0.148

(0.051)

0.548

(0.070)

0.517

(0.104)

Share(Tax Law Specialist)

0.379

0.489

(0.104)

0.368

(0.109)

$(0.049)$

Share(Criminal Law Specialist)

$-0.017$

$(0.080)$

$-0.169$

(0.106)

$-0.062$

(0.093)

Share(Domestic Law Specialist)

$(0.083)$

$-0.020$

$-0.217$

(0.078)

0.603

(0.107)

$-0.265$

(0.057)

Share(Negligence-Plaintiff Specialist)

0.087

$(0.060)$

0.094

0.094
$(0.074)$

$-0.055$

(0.064)

Share(Probate Law Specialist)

0.157
$(0.064)$

$-0.019$

(0.085)

Share(Other Specialist)

0.275

0.160

0.389

$(0.100)$

$(0.048)$

$(0.085)$

(0.032)

(0.035)

(0.037)

$(0.029)$

0.50

0.48

0.61

$\mathrm{N}$

7560

3058

4835

5319

Estimated percent change in earnings from moving from $a p=0.5$ to $a p=1.5: \exp [w(1.5)] / \exp [w(0.5)]$ Business, Non-Litigation Offices Litigation Offices

Individual, Non-Litigation Offices

$\begin{array}{ll}4 \% & 11 \% \\ 7 \% & -2 \% \\ -1 \% & -1 \%\end{array}$

$11 \%$
$-2 \%$

$\begin{array}{cc}15 \% & 11 \% \\ 5 \% & 4 \% \\ -10 \% & -5 \%\end{array}$

The dependent variable in the wage-leverage surface regression is In(average associate pay in the office). Offices with at least one lawyer specializing in insurance or negligence law are classified as "litigation" offices. All other offices are classified as "business" or "individual" depending on whether the majority of their

revenues come from individuals. These regressions include county fixed effects and "business, nonlitigation" and "litigation" dummies as well as the variables above. 


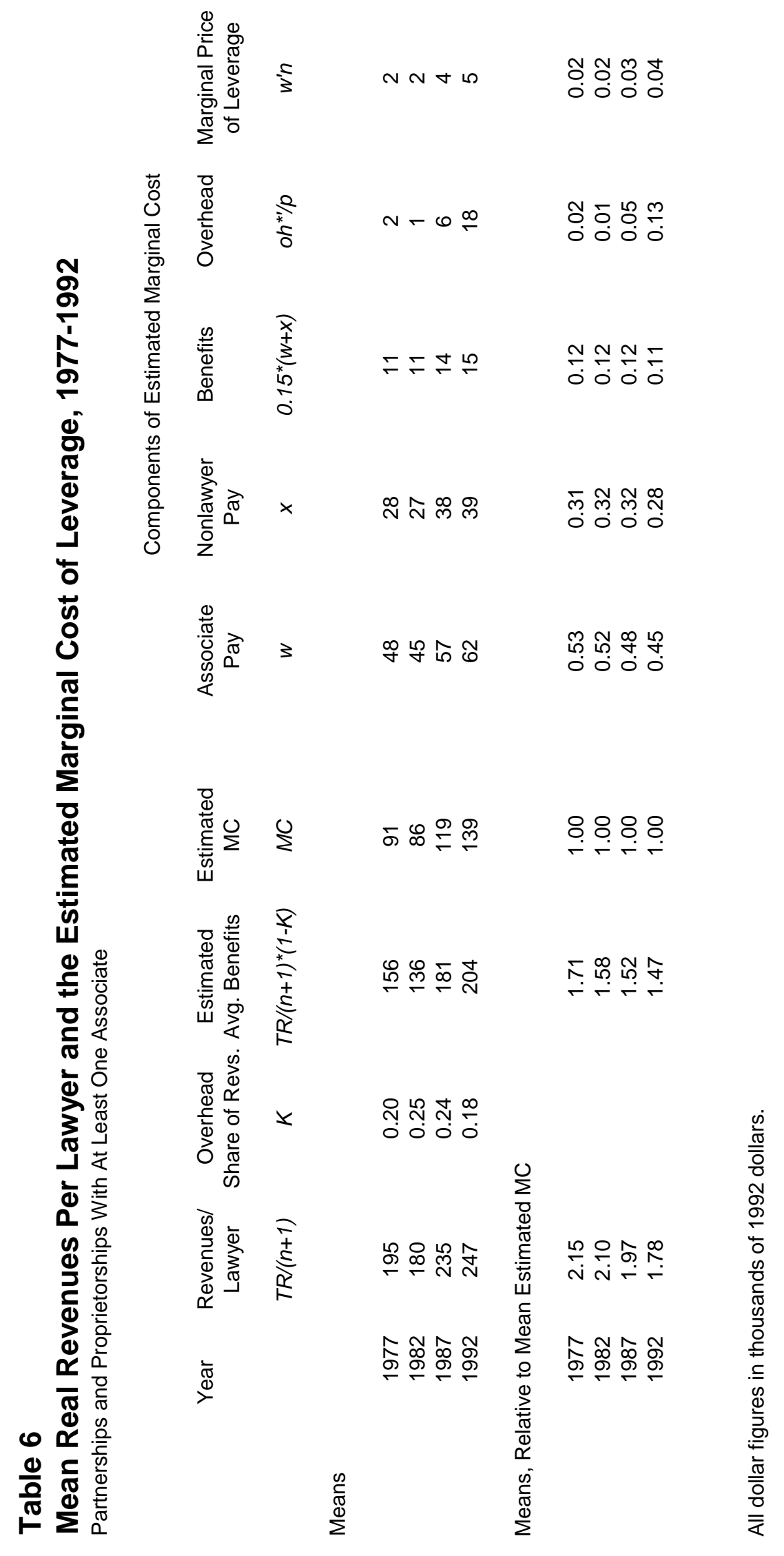


Table 7

Production Function Estimates, 1977-1992

Partnerships and Proprietorships With At Least One Associate

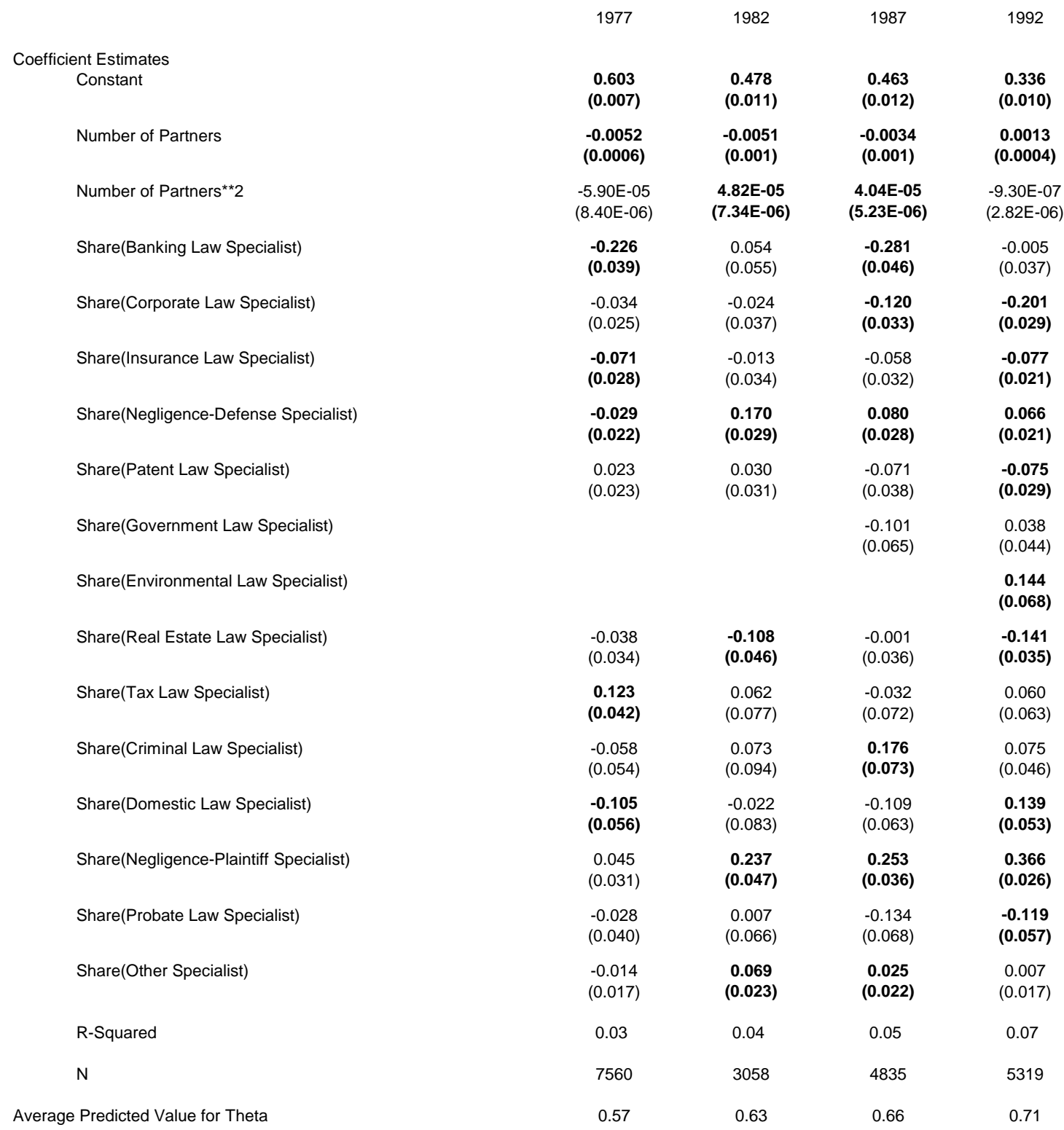

The dependent variable in the production function is $\ln \left(\right.$ revenues/lawyer $\left.{ }^{*}(1-K)\right)-\ln (\mathrm{MC})$, where $\mathrm{K}$ is the coefficient on revenues in the overhead regression for the office, and MC is the estimated marginal cost of leverage for the office. The coefficients reported here correspond to -In(theta) in the text.

The 0.343 coefficient estimate in 1992 for the constant implies an estimate of theta of 0.710 for an office of general practitioners (the omitted category).

Bold indicates rejection of the hypothesis $b=0$ using a one-tailed t-test of size 0.05 . 


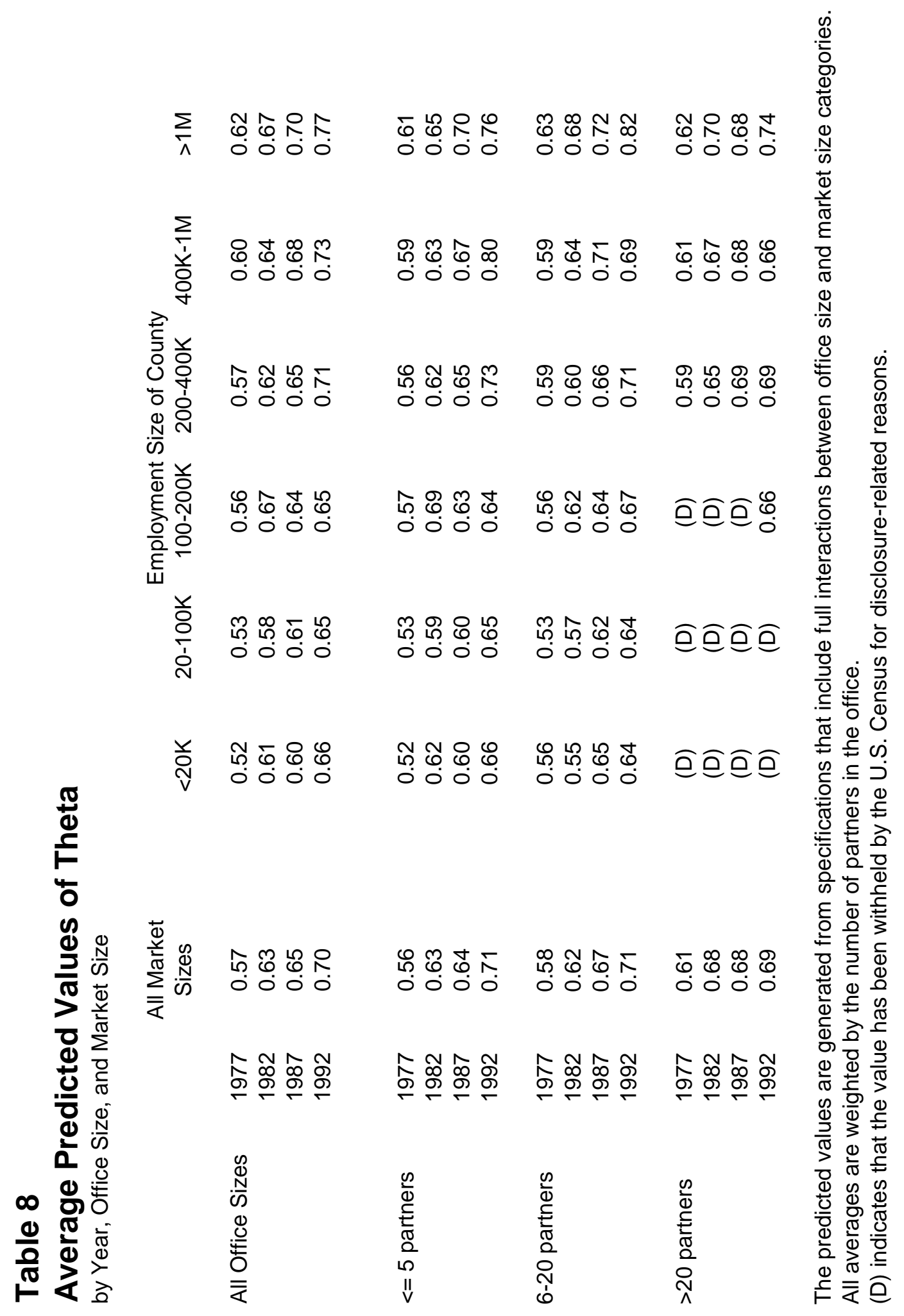




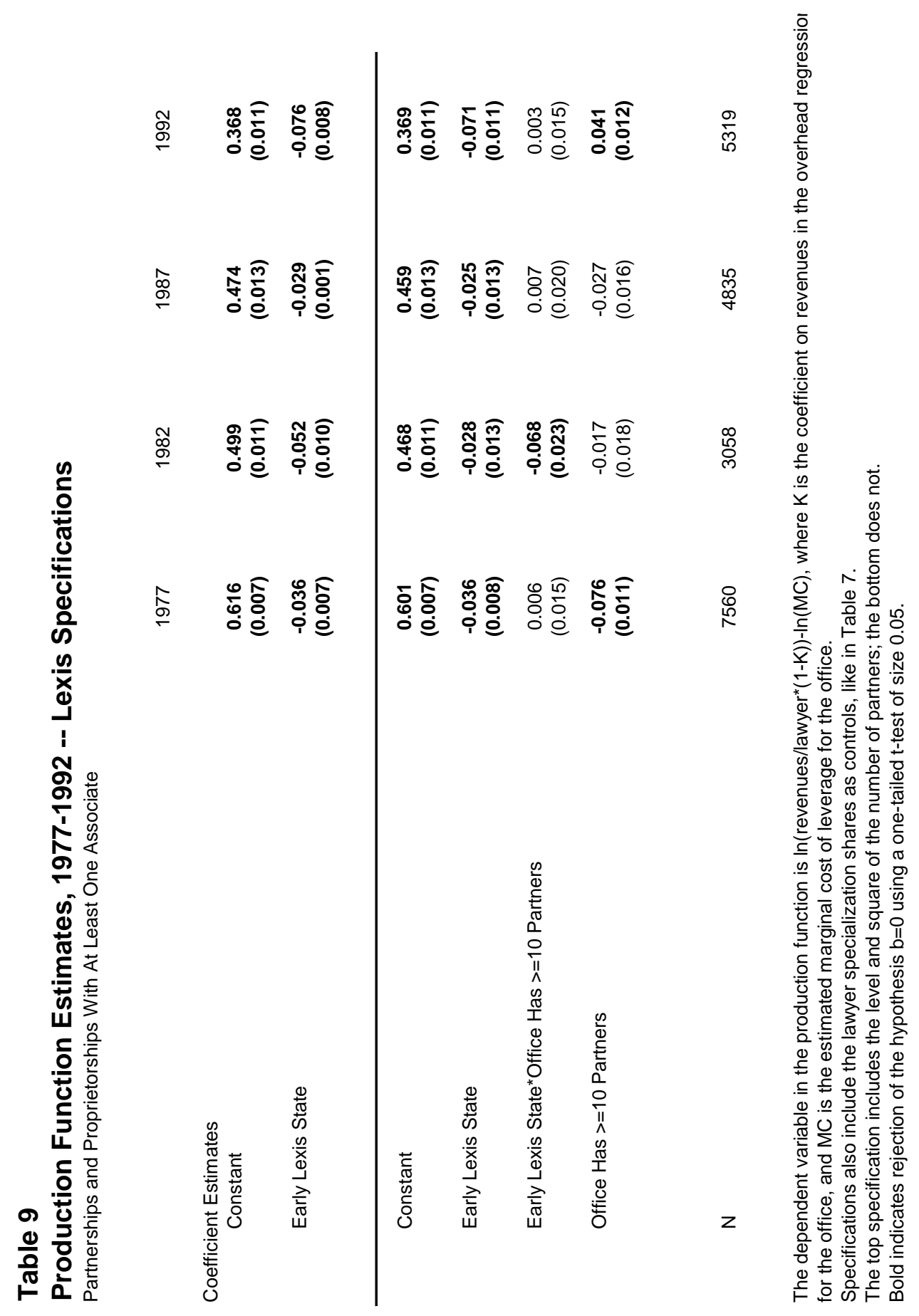




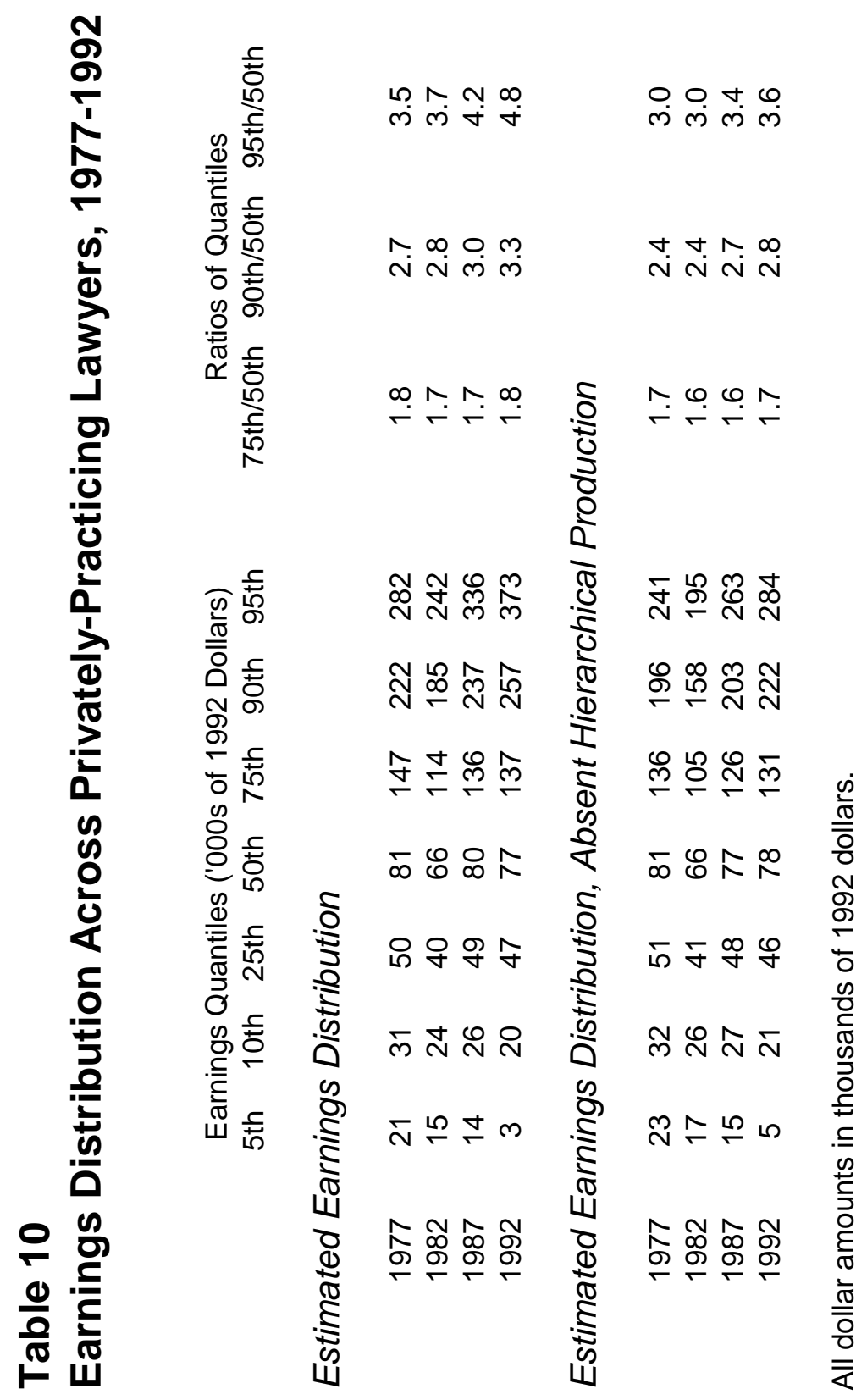


Table 11

Changes in Logged Earnings Quantile Ratios, Privately-Practicing Lawyers, 1977-1992

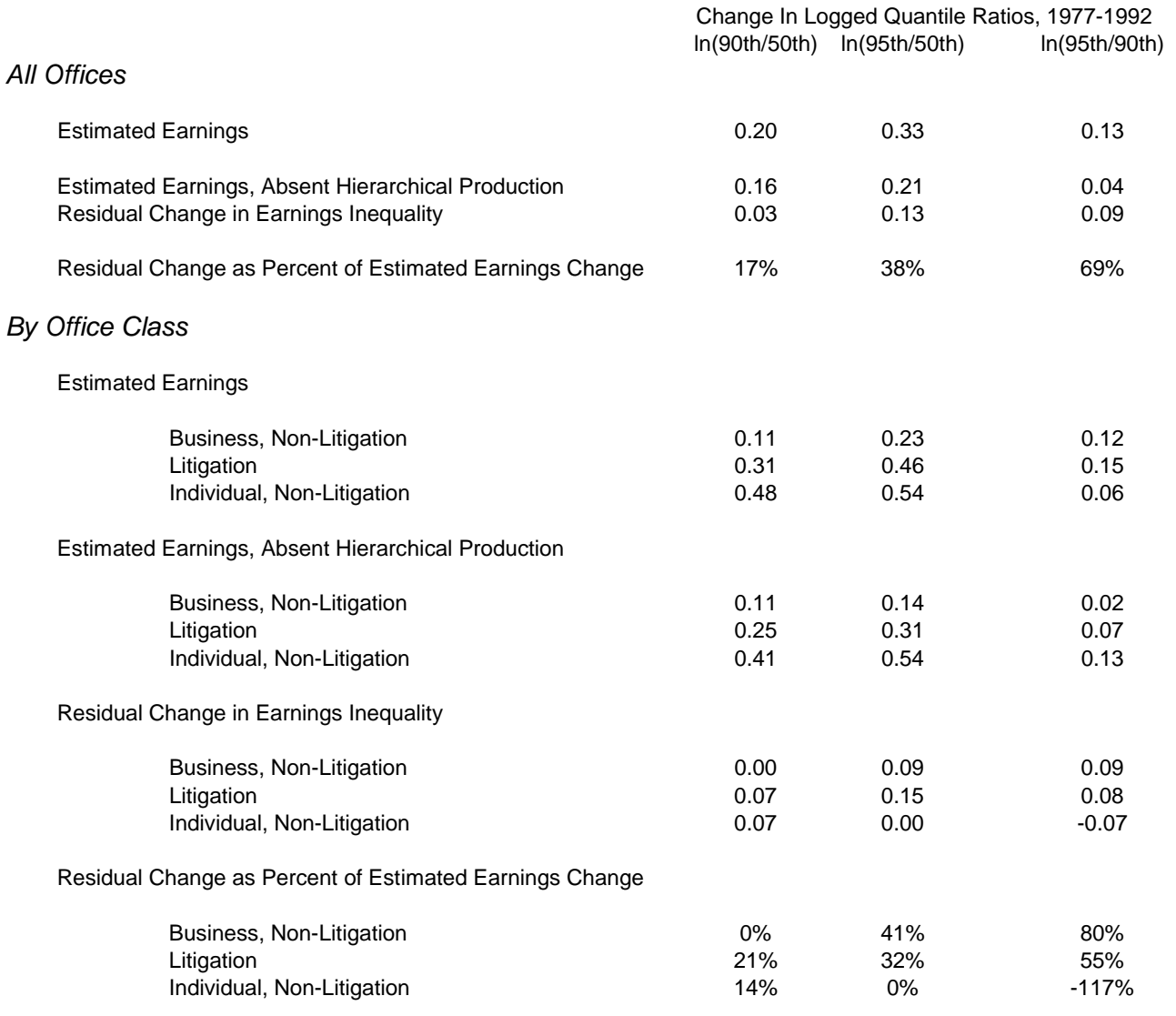

Residual Change in Earnings Inequality is the difference between the figures in the "estimated earnings" panel and the "estimated earnings, absent hierarchical production" panel. This is a measure of the degree to which changes in leverage have affected earnings inequality. 
Table 12

Decomposition of Productivity Changes

Revenues Per Lawyer and Its Components

$\begin{array}{ccccc}\text { Year } & \overline{y_{i} /\left(n_{i}+1\right)} & \overline{z_{m}} & \bar{s} & \operatorname{cov}\left(z_{m i}, s_{i}\right) \\ 1977 & 182 & 222 & 0.86 & -9 \\ 1982 & 167 & 205 & 0.86 & -9 \\ 1987 & 225 & 285 & 0.83 & -13 \\ 1992 & 227 & 280 & 0.86 & -12\end{array}$

Decomposition of Changes in Revenues Per Lawyer

$\begin{array}{ccccc} & \Delta \overline{y_{i} /\left(n_{i}+1\right)} & \Delta \overline{z_{m}} \overline{s_{t}} & \Delta \bar{s} \overline{z_{m, t-1}} & \Delta \operatorname{cov}\left(z_{m i}, s_{i}\right) \\ 1977-1992 & 46 & 49 & 0 & -3\end{array}$

All dollar amounts are in thousands of 1992 dollars. 


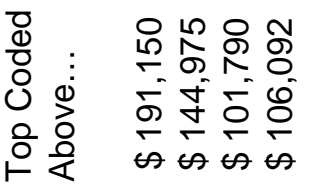

言 $\stackrel{+}{\leftarrow}$ * * *

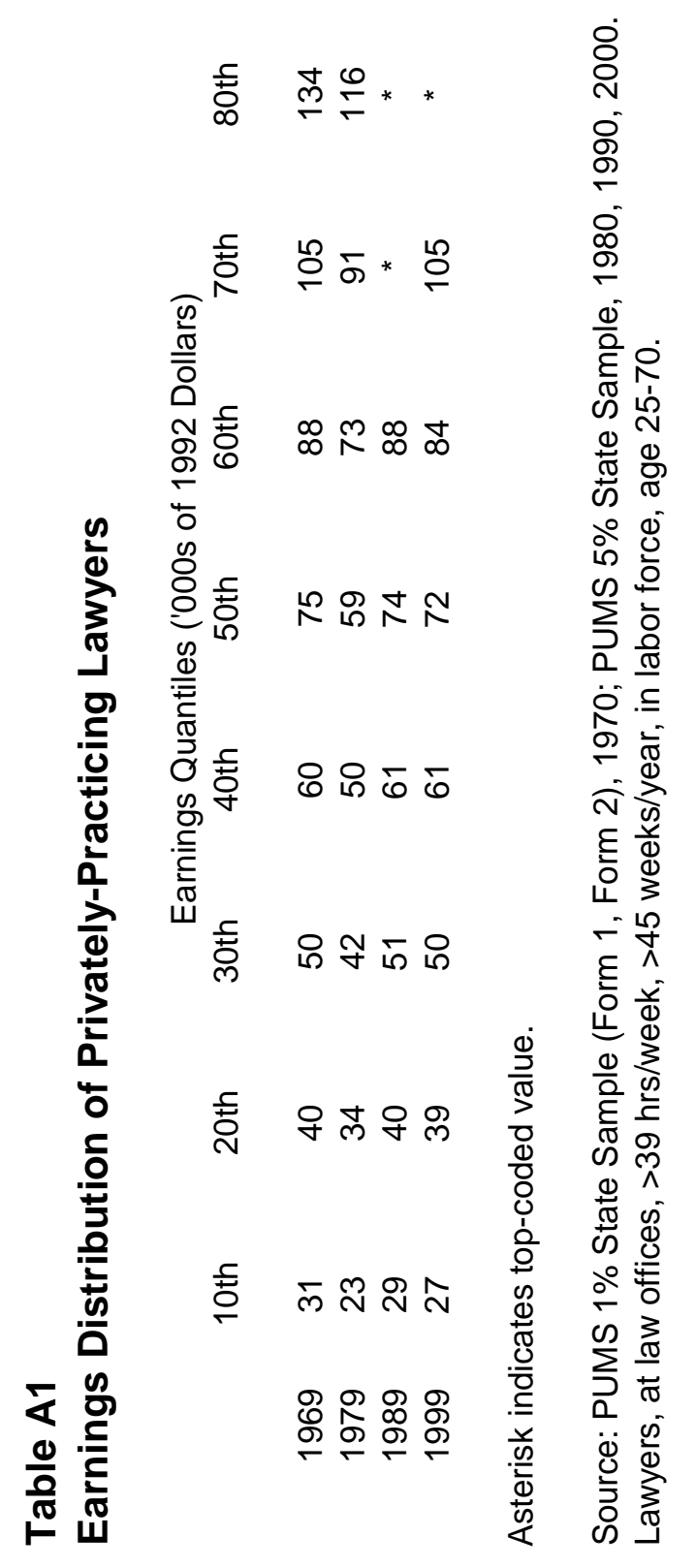



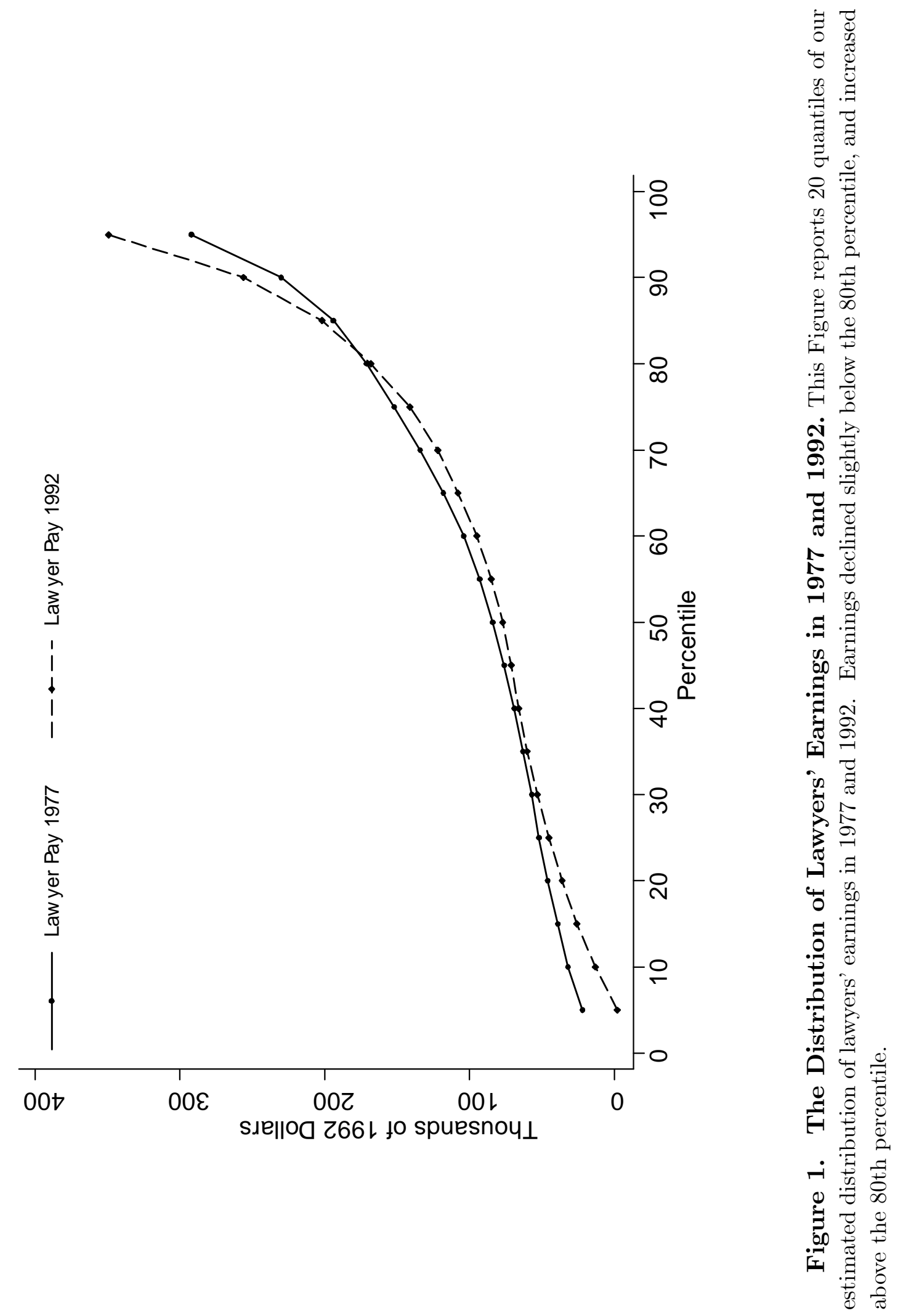


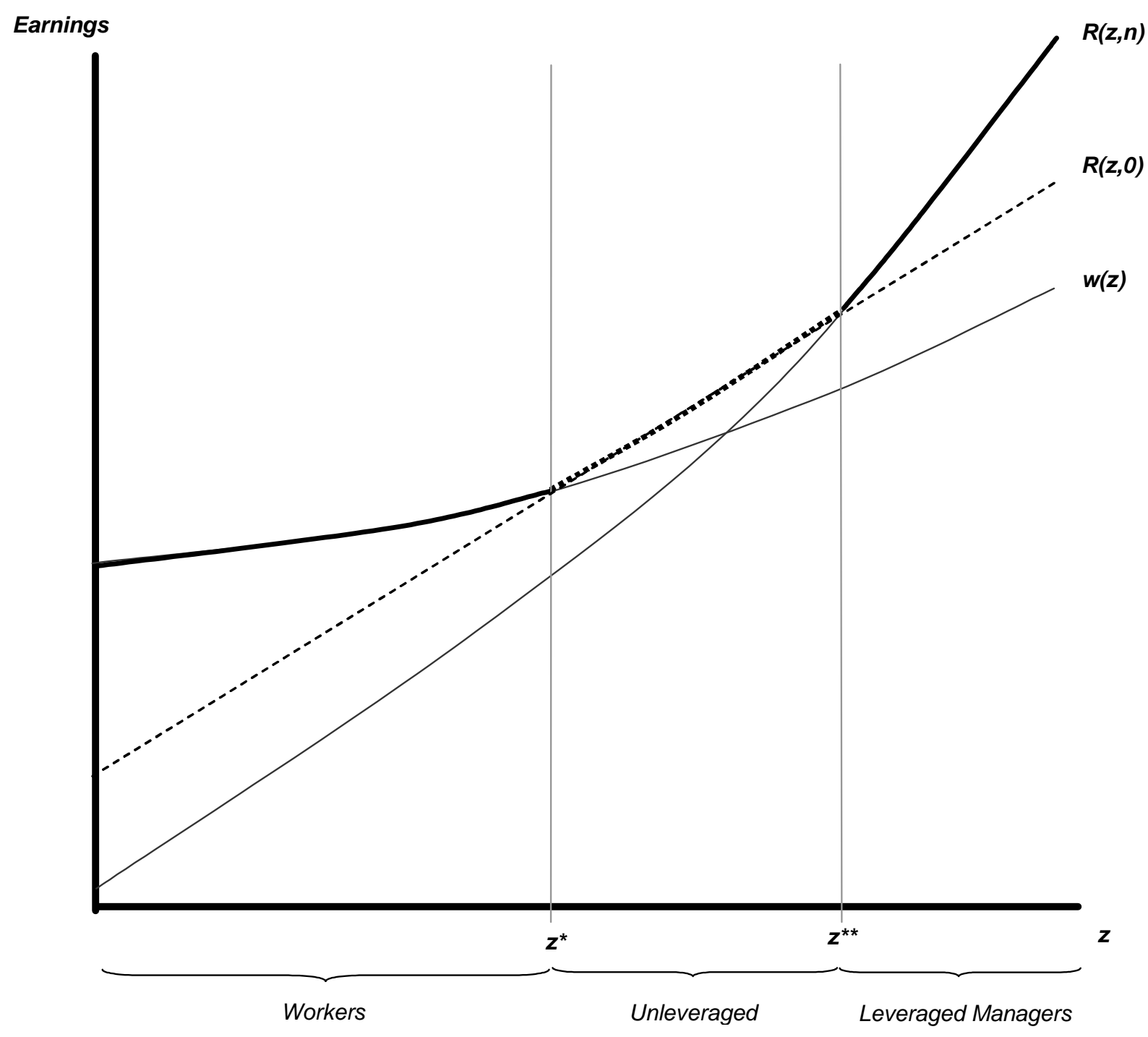

Figure 2. Equilibrium Earnings and Assignment. The three curves in this Figure represent agents' earnings as a function of their skill, $z$, if they are (a) managers with others working under them $(R(z, n))$, (b) working on their own $(R(z, 0))$ and (c) workers working under managers $(w(z))$. The equilibrium wage-skill surface is the outer envelope of these curves, which is in bold. A goal of the empirical work is to estimate how $R(z, 0)$ changes over time. 